\title{
Dysregulated CXCR4 expression promotes Iymphoma cell survival and independently predicts disease progression in germinal center B-cell-like diffuse large B-cell lymphoma
}

Jiayu Chen ${ }^{1,2, *}$ Zijun Y Xu-Monette ${ }^{2, *}$ Lijuan Deng $^{2}$ Qi Shen ${ }^{2}$ Ganiraju C. Manyam ${ }^{3}$, Azahara Martinez-Lopez ${ }^{4}$, Li Zhang ${ }^{3}$, Santiago Montes-Moreno ${ }^{4}$, Carlo Visco $^{5}$, Alexandar Tzankov, ${ }^{6}$ Lihui Yin ${ }^{2}$, Karen Dybkaer7, April Chiu ${ }^{8}$, Attilio Orazi ${ }^{9}$, Youli Zu ${ }^{10}$, Govind Bhagat ${ }^{11}$, Kristy L. Richards ${ }^{12}$, Eric D. Hsi ${ }^{13}$, William W.L. Choi ${ }^{14}$, J. Han van Krieken ${ }^{15}$, Jooryung Huh ${ }^{16}$, Maurilio Ponzoni ${ }^{17}$, Andrés J.M. Ferreri ${ }^{17}$, Xiaoying Zhao ${ }^{18}$, Michael B. Møller ${ }^{19}$, John P. Farnen ${ }^{20}$, Jane N. Winter ${ }^{21}$, Miguel A. Piris $^{4}$, Lan Pham ${ }^{2}$ and Ken H. Young ${ }^{2,22}$

${ }^{1}$ Medical School of Taizhou University, Taizhou, Zhejiang, China

2 Department of Hematopathology, The University of Texas MD Anderson Cancer Center, Houston, TX, USA

${ }^{3}$ Department of Bioinformatics and Computational Biology, The University of Texas MD Anderson Cancer Center, Houston, TX, USA

${ }^{4}$ Hospital Universitario Marques de Valdecilla, Santander, Spain

${ }^{5}$ San Bortolo Hospital, Vicenza, Italy

${ }^{6}$ University Hospital, Basel, Switzerland

${ }^{7}$ Aalborg University Hospital, Aalborg, Denmark

8 Memorial Sloan-Kettering Cancer Center, New York, NY, USA

${ }^{9}$ Weill Medical College of Cornell University, New York, NY, USA

${ }^{10}$ The Methodist Hospital, Houston, TX, USA

${ }^{11}$ Columbia University Medical Center and New York Presbyterian Hospital, New York, NY, USA

12 University of North Carolina School of Medicine, Chapel Hill, NC, USA

${ }^{13}$ Cleveland Clinic, Cleveland, $\mathrm{OH}$, USA

14 University of Hong Kong Li Ka Shing Faculty of Medicine, Hong Kong, China

${ }^{15}$ Radboud University Nijmegen Medical Centre, Nijmegen, Netherlands

${ }^{16}$ Asan Medical Center, Ulsan University College of Medicine, Seoul, Korea

${ }^{17}$ San Raffaele H. Scientific Institute, Milan, Italy

18 Zhejiang University School of Medicine, Second University Hospital, Hangzhou, China

${ }^{19}$ Odense University Hospital, Odense, Denmark

${ }^{20}$ Gundersen Lutheran Health System, La Crosse, WI, USA

${ }^{21}$ Feinberg School of Medicine, Northwestern University, Chicago, IL, USA

22 The University of Texas School of Medicine, Graduate School of Biomedical Sciences, Houston, TX, USA

* These authors made equal contributions to this work

Correspondence to: Ken H. Young, email: khyoung@mdanderson.org

Keywords: CXCR4, DLBCL, BCL2, Myc, TP53 mutation

Received: December 30, $2014 \quad$ Accepted: January 04, 2015

Published: January 21, 2015

This is an open-access article distributed under the terms of the Creative Commons Attribution License, which permits unrestricted use, distribution, and reproduction in any medium, provided the original author and source are credited.

ABSTRACT

Abnormal expression of the chemokine receptor CXCR4 plays an essential role in tumor cell dissemination and disease progression. However, the significance of CXCR4 overexpression in de novo diffuse large B cell lymphoma (DLBCL) is unknown. In 743 
patients with de novo diffuse large B cell lymphoma (DLBCL) who received standard Rituximab-CHOP immunochemotherapy, we assessed the expression of CXCR4 and dissected its prognostic significance in various DLBCL subsets. Our results showed that CXCR4 $^{+}$patients was associated with male, bulky tumor, high Ki-67 index, activated $B-c e l l-l i k e(A B C)$ subtype, and $\mathrm{Myc}, \mathrm{Bcl}-2$ or p53 overexpression. Moreover, CXCR4+ was an independent factor predicting poorer progression-free survival in germinalcenter B-cell-like (GCB)-DLBCL, but not in ABC-DLBCL; and in patients with an IPI of $\leq 2$, but not in those with an IPI $>2$. The lack of prognostic significance of CXCR4 in ABC-DLBCL was likely due to the activation of p53 tumor suppressor attenuating CXCR4 signaling. Furthermore, concurrent CXCR4 ${ }^{+}$and $B C L 2$ translocation showed dismal outcomes resembling but independent of $M Y C / B C L 2$ double-hit DLBCL. Gene expression profiling suggested that alterations in the tumor microenvironment and immune responses, increased tumor proliferation and survival, and the dissemination of $\mathrm{CXCR4}^{+}$tumor cells to distant organs or tissues were underlying molecular mechanisms responsible for the $\mathrm{CXCR}^{+}$associated poor prognosis.

\section{INTRODUCTION}

CXCR4 (CD184) is a chemokine receptor specific for CXCL12. The CXCL12/CXCR4 axis is critical to the retention of $\mathrm{B}$-cell precursors in bone marrow (BM), homing of B lymphocytes to lymph nodes, and infiltration of T-cells and other immune cells expressing CXCR4 [1]. Signaling molecules, physiological stimuli, and co-translational modifications control the expression, oligomerization, internalization, and degradation of CXCR4. CD63, interleukin 21, hypoxia-inducible factor 1 alpha, nuclear factor-kappa B (NF-kB), CREB3, PAX3FKHR, Wnt, Notch, and PI3K/Akt pathways positively regulate CXCR4 levels. In contrast, p53 [2], tumor necrosis factor-alpha (TNF- $\alpha$ ), interferon-gamma, and ubiquitination modification negatively regulate CXCR4 levels [3-6]. Activated CXCL12/CXCR4 in turn activates signaling cascades such as PI3K/Akt, mitogen-activated protein kinase (MAPK), integrin, tyrosine kinases, and G-proteins $[3,4]$.

Abnormal CXCR4 surface expression in solid tumors, has been shown to be responsible for their metastasis to particular organs with high CXCL12 levels (e.g., lymph nodes, bones, and BM) [3,7,8], and have prognostic significance for disease progression in breast, colorectal, and renal cancers, and hepatocellular carcinoma $[3,9,10]$. In leukemia, CXCR4 expression conferred leukemic blasts with a higher capacity to seed into BM niches, thereby protecting leukemic cells from chemotherapy-induced apoptosis, and was correlated with shorter disease-free survival [3,11-15]. Conversely, neutralizing the interactions of CXCL12/CXCR4 disrupted metastasis, induced apoptosis, and increased chemosensitivity in solid cancers and leukemia [7,16-18].

Diffuse large B cell lymphoma (DLBCL) is the most common type of non-Hodgkin lymphoma among adults. DLBCL typically presents as a nodal or extranodal mass with rapid tumor growth. Extranodal DLBCL (primary sites are outside the lymphatic system) accounts for 30-
$40 \%$ of DLBCL. Approximately $70 \%$ of DLBCLs have at least one and $30 \%$ have multiple extranodal involvements $[19,20]$. With the standard immunochemotherapy regimen consisting of rituximab, cyclophosphamide, doxorubicin, vincristine, and prednisone (R-CHOP), approximately one-third of DLBCL patients develop relapsed/refractory disease [21]. Gene expression profiling (GEP) divides DLBCL into two main subtypes according to cell-oforigin gene signatures: germinal center B-cell-like (GCB), arising from the germinal center (GC) compartment, and activated B-cell-like (ABC), arising from post-GC plasmablastic cells [22]. During the development of mature B-cells, CXCR4 is expressed at higher levels in centroblasts localized in the CXCL12-rich dark zone than in centrocytes in the light zone of the GC. CXCR4 is also upregulated during plasma cell differentiation and expressed in memory B-cells [23-27].

The prognostic significance of CXCR4 expression in lymphoma, which has different CXCL12 gradients at the primary sites compared to other types of cancers [28], has not been well studied. Moreover, it is unknown whether the use of a CXCL12/CXCR4 antagonist in nodal DLBCL will result in lymphoma cell mobilization and increased spreading [8,29-32]. Very recently, CXCR4 expression was correlated to disease progression in 12 cases of primary testicular DLBCL [33] and poor survival of 94 DLBCL cases [34]. In 20 patients with non-Hodgkin lymphomas, a significant decrease in CXCR4 mRNA expression in the $\mathrm{BM}$ after treatment correlated with a significantly lower risk of death [35]. In this study, we assessed the surface expression of CXCR4 using immunohistochemistry (IHC) in 743 patients with de novo DLBCL, compared the gene expression profiles and protein expression of biomarkers between CXCR4 $4^{+}$and CXCR4- DLBCLs, and evaluated the prognostic value of CXCR4 expression. We also tested the effect of the high-affinity CXCL12/CXCR4 inhibitor BTK140 (4F-benzoyl-TN14003) on DLBCL cells in vitro, which not only inhibits CXCL12/CXCR4 mediated adhesion and migration [36], overcomes stromal cells- 
mediated chemoresistance, but also has direct cytotoxic activities in non-Hodgkin lymphoma cell lines, leukemic and multiple myeloma cells in a CXCR4-dependent and dose-dependent manner [29,37].

\section{RESULTS}

\section{CXCR4 and CXCL12 expression}

IHC results (representative positive and negative staining was shown in Figures $1 \mathrm{~A}-\mathrm{C}$ ) indicated that in most of the DLBCLs, CXCR4 surface expression level was low (Figure 1D, Supplemental Figures 1AB). The mean expression level in the 468 DLBCLs of the training set was $20 \%$ of tumor cells positive for CXCR4 cell surface expression, which was used as the cutoff for CXCR4 overexpression (CXCR4 ${ }^{+}$). Using this cutoff ( $\geq 20 \%$ ), we found that $28.8 \%$ of the samples in the training cohort were CXCR4 $4^{+}$.

CXCR4 cell surface expression and mRNA levels were higher in the ABC than GCB subtype, whereas CXCL12 mRNA levels did not differ significantly between the two groups (Figures 1E-F, Supplemental Figure 1C). CXCR4 expression detected via IHC was significantly correlated with CXCR4 mRNA levels $(P<.0001$, Supplemental Figure 1D), and intriguingly, significantly correlated with lower CXCL12 mRNA levels (Figure 1G).

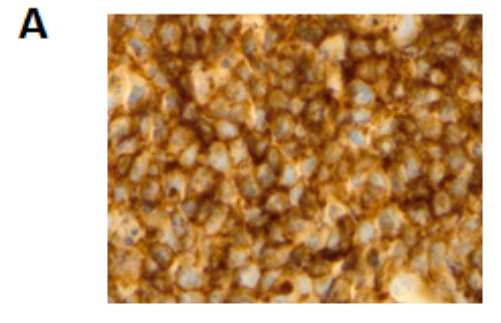

B
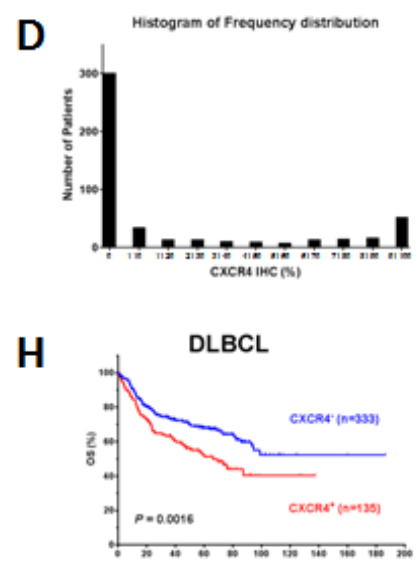

E
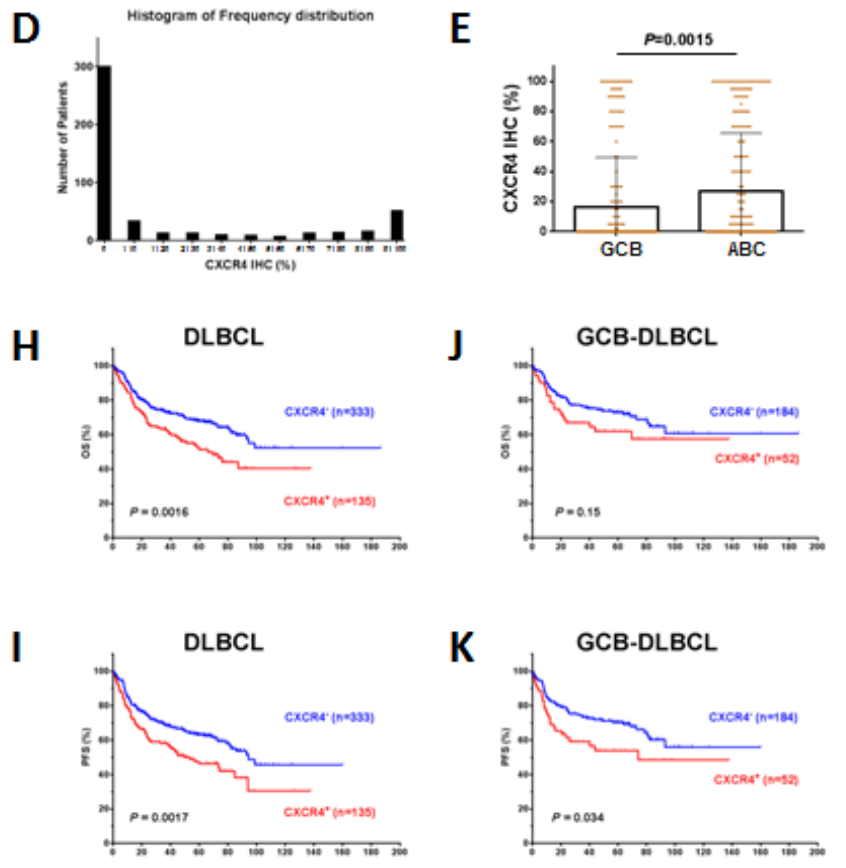

Months

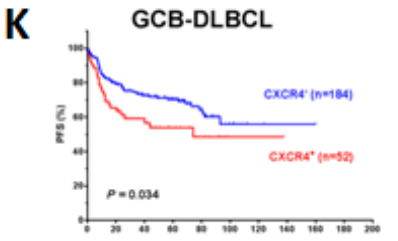

Months
F

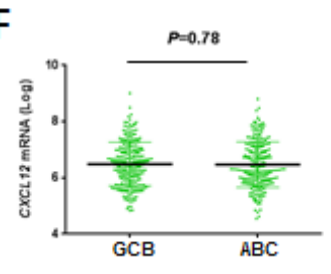

$\mathbf{L}$
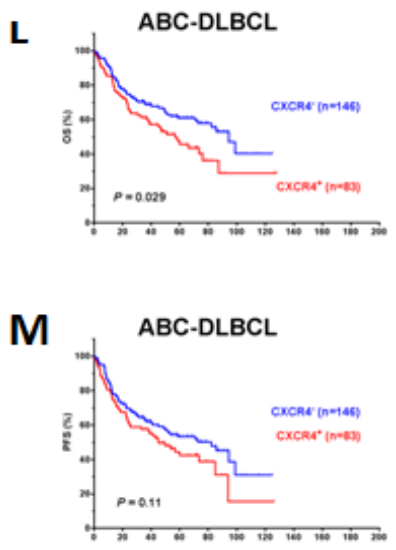

Months
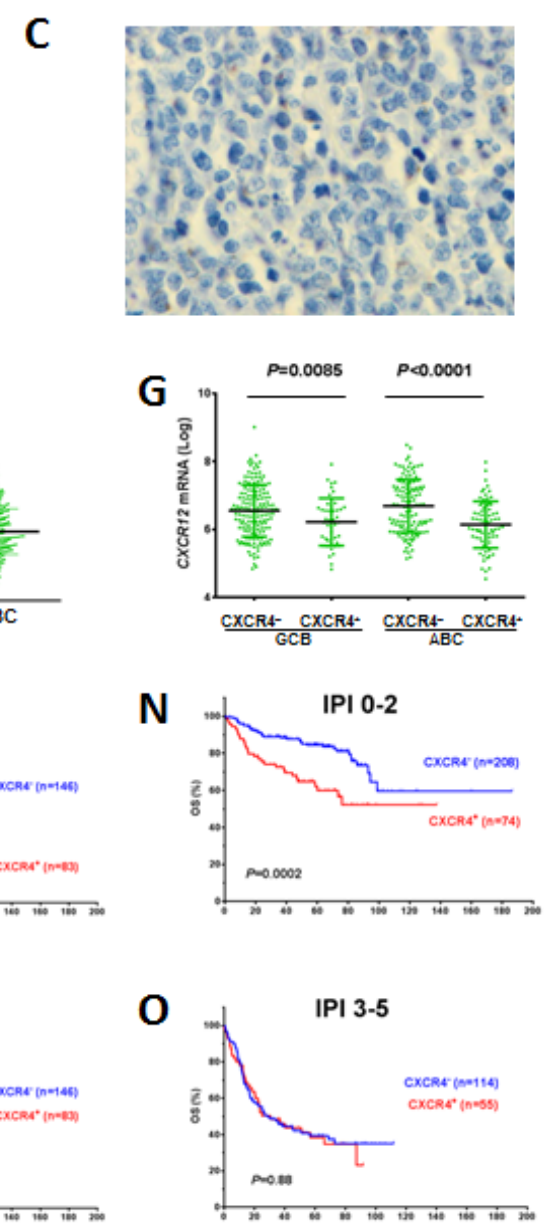

Months

Figure 1: Expression and prognostic significance of CXCR4 in DLBCL. (A-C) Representative CXCR4 immunohistochemistry staining (showing 100\%, 60\%, 0\% CXCR4 cell surface expression in DLBCL cells). (D) Histogram of CXCR4 expression frequency distribution in the DLBCL study cohort. X-axis, percentage of immunopositive cells in tumors; Y-axis, numbers of DLBCL patients. (E-F) ABC-DLBCL compared to GCB-DLBCL had increased CXCR4 cell surface expression, but did not differ in CXCL12 mRNA significantly. (G) CXCR4 cell surface expression correlated with decreased CXCL12 mRNA levels, both in GCB- and ABC-DLBCL. (HI) CXCR4 expression correlated with significantly poorer OS and PFS in the overall DLBCL cohort. (J-K) CXCR4 expression correlated with significantly poorer PFS (but not OS) in GCB-DLBCL. (L-M) CXCR4 expression correlated with significantly poorer OS (but not PFS) in ABC-DLBCL. (N-O) CXCR4 expression correlated with significantly poorer survival in DLBCL patients with a low IPI, but not in DLBCL patients with a high IPI. 
Table 1: Clinical features of patients with $\mathrm{CXCR4}^{+}$and $\mathrm{CXCR} 4^{-}$expression in overall, GCBDLBCL and ABC-DLBCL

\begin{tabular}{|c|c|c|c|c|c|c|c|c|c|}
\hline \multirow[b]{2}{*}{ Variables } & \multicolumn{2}{|c|}{ DLBCL } & \multirow[b]{2}{*}{$P$} & \multicolumn{2}{|c|}{ GCB-DLBCL } & \multirow[b]{2}{*}{$P$} & \multicolumn{2}{|c|}{ ABC-DLBCL } & \multirow[b]{2}{*}{$P$} \\
\hline & $\begin{array}{c}\text { CXCR4 }^{+} \\
N(\%)\end{array}$ & $\begin{array}{c}\text { CXCR4 } \\
\mathrm{N}(\%)\end{array}$ & & $\begin{array}{c}\text { CXCR4 }^{+} \\
N(\%)\end{array}$ & $\begin{array}{c}\text { CXCR4 } \\
\mathrm{N}(\%)\end{array}$ & & $\begin{array}{c}\text { CXCR4 }^{+} \\
N(\%)\end{array}$ & $\begin{array}{c}\text { CXCR4 } \\
N(\%)\end{array}$ & \\
\hline \multicolumn{10}{|l|}{ Age, years } \\
\hline$<60$ & $51(37.8)$ & $147(44.1)$ & .21 & $28(53.8)$ & $93(50.5)$ & .67 & $23(27.7)$ & $53(36.3)$ & .18 \\
\hline$\geq 60$ & $84(62.2)$ & $18655.9 \%$ & & $24(46.2)$ & $91(49.5)$ & & $60(72.3)$ & $93(63.7)$ & \\
\hline \multicolumn{10}{|l|}{ Gender } \\
\hline $\mathrm{F}$ & $40(29.6)$ & $148(44.4)$ & .0031 & $18(34.6)$ & $78(42.4)$ & .31 & $22(26.5)$ & $69(47.3)$ & .002 \\
\hline$M$ & $95(70.4)$ & $185(55.6)$ & & $34(65.4)$ & $106(57.6)$ & & $61(73.5)$ & $77(52.7)$ & \\
\hline \multicolumn{10}{|l|}{ Stage } \\
\hline I - II & $56(42.4)$ & $155(48.3)$ & .26 & $23(45.1)$ & $98(55.7)$ & .18 & $33(40.7)$ & $55(39)$ & .80 \\
\hline III - IV & $76(57.6)$ & $166(51.7)$ & & $28(54.9)$ & $78(44.3)$ & & $48(59.3)$ & $86(61.0)$ & \\
\hline \multicolumn{10}{|c|}{ B-symptoms } \\
\hline No & $84(65.6)$ & $206(64.8)$ & .87 & $34(70.8)$ & $123(70.3)$ & .94 & $50(62.5)$ & $80(57.6)$ & .47 \\
\hline Yes & $44(34.4)$ & $112(35.2)$ & & $14(29.2)$ & $52(29.7)$ & & $30(37.5)$ & $59(42.4)$ & \\
\hline \multicolumn{10}{|l|}{ LDH level } \\
\hline Normal & $45(36.6)$ & $122(39.9)$ & .53 & $19(42.2)$ & $72(42.6)$ & .96 & $26(33.3)$ & $49(36.8)$ & .61 \\
\hline Elevated & $78(63.4)$ & $184(60.1)$ & & $26(57.8)$ & $97(57.4)$ & & $52(66.7)$ & $84(63.2)$ & \\
\hline \multicolumn{10}{|c|}{ Number of extranodal sites } \\
\hline $0-1$ & $94(73.3)$ & $251(79.9)$ & .089 & $35(72.9)$ & $140(80)$ & .29 & $59(71.1)$ & $108(77.7)$ & .27 \\
\hline$\geq 2$ & $37(26.7)$ & $66(20.1)$ & & $13(27.1)$ & $35(20)$ & & $24(28.9)$ & $31(22.3)$ & \\
\hline \multicolumn{10}{|c|}{ ECOG Performance status } \\
\hline $0-1$ & $104(85.2)$ & $243(82.9)$ & .56 & $39(90.7)$ & $134(83.8)$ & .25 & $65(82.3)$ & $106(81.5)$ & .89 \\
\hline$\geq 2$ & $18(14.8)$ & $50(17.1)$ & & $4(9.3)$ & $26(16.3)$ & & $14(17.7)$ & $24(18.5)$ & \\
\hline \multicolumn{10}{|c|}{ Size of largest tumor } \\
\hline$<5 \mathrm{~cm}$ & $55(49.1)$ & $151(62.1)$ & .02 & $22(75.9)$ & $82(60.3)$ & .11 & $33(45.2)$ & $67(65)$ & .0088 \\
\hline$\geq 5 \mathrm{~cm}$ & $57(50.9)$ & $92(37.9)$ & & $7(24.1)$ & $54(39.7)$ & & $40(54.8)$ & $36(35)$ & \\
\hline \multicolumn{10}{|l|}{ IPI score } \\
\hline $0-2$ & $74(57.4)$ & $208(64.4)$ & .16 & $31(64.6)$ & $125(70.6)$ & .42 & $43(53.1)$ & $80(56.3)$ & .64 \\
\hline $3-5$ & $55(42.6)$ & $115(35.6)$ & & $17(35.4)$ & $52(29.4)$ & & $38(46.9)$ & $62(43.7)$ & \\
\hline \multicolumn{10}{|c|}{ Therapy response } \\
\hline CR & $102(75.6)$ & $261(78.4)$ & .51 & $35(67.3)$ & $148(80.4)$ & .045 & $67(80.7)$ & $111(76)$ & .41 \\
\hline PR & 13 & 45 & & 5 & 21 & & 8 & 24 & \\
\hline SD & 8 & 11 & & 5 & 7 & & 3 & 4 & \\
\hline PD & 12 & 16 & & 7 & 8 & & 5 & 7 & \\
\hline \multicolumn{10}{|l|}{ coo } \\
\hline GCB & $52(38.5)$ & $184(55.8)$ & .0008 & & & & & & \\
\hline $\mathrm{ABC}$ & $83(61.5)$ & $146(44.2)$ & & & & & & & \\
\hline
\end{tabular}

Abbreviations: LDH, lactate dehydrogenase; IPI, International Prognostic Index; CR, complete remission; PR, partial response; SD, stable disease; $\mathrm{PD}$, progressive disease; COO, cell-of-origin. For therapy response, we calculated $P$ values as $\mathrm{CR}$ vs other responses. Few clinical features of certain cases were not available. 
Table 2: Pathological features of patients with $\mathrm{CXCR4}^{+}$and $\mathrm{CXCR4}^{-}$expression in overall, GCBDLBCL and ABC-DLBCL

\begin{tabular}{|c|c|c|c|c|c|c|c|c|c|}
\hline \multirow[b]{2}{*}{ Variables } & \multicolumn{2}{|c|}{ DLBCL } & \multirow[b]{2}{*}{$P$} & \multicolumn{2}{|c|}{ GCB-DLBCL } & \multirow[b]{2}{*}{$P$} & \multicolumn{2}{|c|}{ ABC-DLBCL } & \multirow[b]{2}{*}{$P$} \\
\hline & $\begin{array}{c}\mathrm{CXCR4}^{+} \\
\mathrm{N}(\%)\end{array}$ & $\begin{array}{c}\text { CXCR4 } \\
N(\%)\end{array}$ & & $\begin{array}{c}\mathrm{CXCR4}^{+} \\
\mathrm{N}(\%)\end{array}$ & $\begin{array}{c}\text { CXCR4 } \\
N(\%)\end{array}$ & & $\begin{array}{c}\mathrm{CXCR4}^{+} \\
\mathrm{N}(\%)\end{array}$ & $\begin{array}{c}\text { CXCR4 } \\
N(\%)\end{array}$ & \\
\hline \multicolumn{10}{|c|}{ Ki-67 index } \\
\hline$<70 \%$ & $28(20.7)$ & $137(42.3)$ & $<.0001$ & $11(21.2)$ & $79(44.6)$ & .002 & $17(20.5)$ & $57(39)$ & .005 \\
\hline$\geq 70 \%$ & $107(79.3)$ & $187(57.7)$ & & $41(78.8)$ & $98(55.4)$ & & $66(79.5)$ & $89(61)$ & \\
\hline \multicolumn{10}{|c|}{ TP53 mutations } \\
\hline No & $94(74)$ & $241(80.9)$ & .07 & $29(61.7)$ & $133(78.7)$ & .017 & $65(81.3)$ & $105(83.3)$ & .70 \\
\hline Yes & $33(26)$ & $57(19.1)$ & & $18(38.3)$ & $36(21.3)$ & & $15(18.8)$ & $21(16.7)$ & \\
\hline \multicolumn{10}{|c|}{$M Y C$ translocation } \\
\hline No & $83(85.6)$ & $198(91.7)$ & .11 & $25(80.6)$ & $102(87.9)$ & .37 & $58(87.9)$ & $95(96)$ & .067 \\
\hline Yes & $14(14.4)$ & $18(8.3)$ & & $6(19.4)$ & $14(12.1)$ & & $8(12.1)$ & $4(4)$ & \\
\hline \multicolumn{10}{|c|}{$B C L 2$ translocation } \\
\hline No & $101(83.5)$ & $227(82.2)$ & .89 & $29(67.4)$ & $107(70.4)$ & .71 & $72(92.3)$ & $119(97.5)$ & .16 \\
\hline Yes & $20(16.5)$ & $49(17.8)$ & & $14(32.6)$ & $45(29.6)$ & & $6(7.7)$ & $3(2.5)$ & \\
\hline \multicolumn{10}{|c|}{ BCL6 translocation } \\
\hline No & $73(83)$ & $150(64.4)$ & .0013 & $32(82.1)$ & $95(73.1)$ & .26 & $41(69.5)$ & $54(52.9)$ & .04 \\
\hline Yes & $15(17)$ & $83(35.6)$ & & $7(17.9)$ & $35(26.9)$ & & $18(30.5)$ & $48(47.1)$ & \\
\hline \multicolumn{10}{|c|}{ p53 overexpression } \\
\hline$<20 \%$ & $71(57.3)$ & $195(67.7)$ & .044 & $29(63)$ & $104(63.8)$ & 1.00 & $42(53.8)$ & $91(72.8)$ & .0065 \\
\hline$\geq 20 \%$ & $53(42.7)$ & $93(32.3)$ & & $17(37)$ & $59(36.2)$ & & $36(46.2)$ & $34(27.2)$ & \\
\hline \multicolumn{10}{|c|}{ Myc overexpression } \\
\hline$<70 \%$ & $73(57.9)$ & $221(72.5)$ & .0044 & $31(60.8)$ & $126(78.3)$ & .017 & $42(56)$ & $93(65)$ & .24 \\
\hline$\geq 70 \%$ & $53(42.1)$ & $84(27.5)$ & & $20(39.2)$ & $35(21.7)$ & & $33(44)$ & $50(35)$ & \\
\hline \multicolumn{10}{|c|}{ Bcl-2 overexpression } \\
\hline$<70 \%$ & $48(35.8)$ & $175(53.7)$ & .0007 & $24(47.1)$ & $108(60)$ & .11 & $24(28.9)$ & $65(45.1)$ & .017 \\
\hline$\geq 70 \%$ & $86(64.2)$ & $151(46.3)$ & & $27(52.9)$ & $72(40)$ & & $59(71.1)$ & $79(54.9)$ & \\
\hline \multicolumn{10}{|c|}{ GCET1 overexpression } \\
\hline$<50 \%$ & $84(63.2)$ & $219(67.6)$ & .38 & $21(40.4)$ & $89(49.7)$ & .27 & $63(77.8)$ & $129(89.6)$ & .019 \\
\hline$\geq 50 \%$ & $49(36.8)$ & $105(32.4)$ & & $31(59.6)$ & $90(50.3)$ & & $18(22.2)$ & $15(10.4)$ & \\
\hline \multicolumn{10}{|c|}{ FOXP1 overexpression } \\
\hline$<60 \%$ & $33(24.4)$ & $151(46.3)$ & $<.0001$ & $26(50)$ & $118(65.6)$ & .05 & $7(8.4)$ & $33(22.6)$ & .0065 \\
\hline$\geq 60 \%$ & $102(75.6)$ & $175(53.7)$ & & $26(50)$ & $62(34.4)$ & & $76(91.6)$ & $113(77.4)$ & \\
\hline \multicolumn{10}{|c|}{ MUM1 overexpression } \\
\hline$<30 \%$ & $43(31.9)$ & $181(55.7)$ & $<.0001$ & $34(65.4)$ & $137(76.1)$ & .15 & $9(10.8)$ & $44(30.3)$ & .006 \\
\hline$\geq 30 \%$ & $92(68.1)$ & $144(44.3)$ & & $18(34.6)$ & $43(23.9)$ & & $74(89.2)$ & $101(69.7)$ & \\
\hline \multicolumn{10}{|c|}{ PI3K overexpression } \\
\hline$<70 \%$ & $80(61.5)$ & $233(73.7)$ & .012 & $36(73.5)$ & $130(73.4)$ & 1.00 & $44(54.3)$ & $103(74.6)$ & .0028 \\
\hline$\geq 70 \%$ & $50(38.5)$ & $83(26.3)$ & & $1326.5 \%$ & $47(26.6)$ & & $37(45.7)$ & $35(25.4)$ & \\
\hline \multicolumn{10}{|c|}{ BLIMP-1 expression } \\
\hline$<10 \%$ & $97(75.2)$ & $233(72.6)$ & .64 & $47(95.9)$ & $144(80.9)$ & .008 & $50(62.5)$ & $88(62)$ & 1.00 \\
\hline$\geq 10 \%$ & $32(24.8)$ & $88(27.4)$ & & $2(4.1)$ & $34(19.1)$ & & $30(37.5)$ & $54(38)$ & \\
\hline \multicolumn{10}{|l|}{ p50 } \\
\hline Negative & $74(57.4)$ & $135(44.4)$ & .016 & $34(66.7)$ & $93(54.7)$ & .15 & $40(51.3)$ & $42(31.3)$ & .0054 \\
\hline Positive & $55(42.6)$ & $169(55.6)$ & & $17(33.3)$ & $77(45.3)$ & & $38(48.7)$ & $92(68.7)$ & \\
\hline
\end{tabular}




\begin{tabular}{|lccccccccc|}
\hline p52 & & & & & & & & & \\
Negative & $100(77.5)$ & $210(67.7)$ & .05 & $38(77.6)$ & $114(67.1)$ & .21 & $62(77.5)$ & $96(68.6)$ & .17 \\
Positive & $29(22.5)$ & $100(32.3)$ & & $11(22.4)$ & $56(32.9)$ & & $18(22.5)$ & $44(31.4)$ & \\
p65 & & & & & & & & & \\
Negative & $60(45.8)$ & $129(40.7)$ & .34 & $22(44)$ & $65(37.8)$ & .51 & $38(46.9)$ & $61(42.7)$ & .58 \\
Positive & $71(54.2)$ & $188(59.3)$ & & $28(56)$ & $107(62.2)$ & & $43(53.1)$ & $82(57.3)$ & \\
RelB & & & & & & & & & \\
Negative & $117(92.1)$ & $253(82.4)$ & .01 & $46(95.8)$ & $143(83.6)$ & .03 & $71(89.9)$ & $109(80.7)$ & .08 \\
Positive & $10(7.9)$ & $54(17.6)$ & & $2(4.2)$ & $28(16.4)$ & & $8(10.1)$ & $26(19.3)$ & \\
c-Rel & & & & & & & & & \\
Negative & $89(68.5)$ & $208(69.3)$ & .91 & $31(62)$ & $121(72.9)$ & .16 & $58(72.5)$ & $87(64.9)$ & .29 \\
Positive & $41(31.5)$ & $92(30.7)$ & & $19(38)$ & $45(27.1)$ & & $22(27.5)$ & $47(35.1)$ \\
\hline
\end{tabular}

\section{Clinicopathologic features of patients with CXCR4 expression}

Clinically, CXCR4 $4^{+}$group had higher proportion of male patients and patients with bulky tumors than the CXCR4 - group, and tended to have higher frequency of $>1$ extranodal involvement $(P=.089)$ (Table 1). Pathologically, CXCR4 ${ }^{+}$GCB-DLBCLs compared to CXCR4- GCB-DLBCLs more frequently had a high Ki-67 index, TP53 mutations, Myc overexpression and less frequently expressed BLIMP-1 or nuclear RelB. In comparison, $\mathrm{CXCR}^{+} \mathrm{ABC}-\mathrm{DLBCLs}$ compared to CXCR4- ABC-DLBCLs had a higher percentage of patients with a high Ki-67 index, p53, Myc, Bcl-2, PI3K expression and lower occurrence of $B C L 6$ translocations and nuclear p50 expression (Table 2).

\section{CXCR4 expression was associated with significantly poorer survival}

CXCR4 ${ }^{+}$DLBCL patients had significantly poorer overall survival (OS) $(P=.0016)$ and progression-free survival (PFS) $(P=.0017)$ in the study group (Figures $1 \mathrm{H}-\mathrm{I})$. When examined in the GCB and ABC subtypes, the adverse impact was significant for the PFS of patients with $\mathrm{CXCR}^{+}$GCB-DLBCL (Figure 1K), and the OS of patients with $\mathrm{CXCR}^{+}$ABC-DLBCL (Figure 1L). Further multivariate analysis adjusting for clinical factors of the study cohort indicated that $\mathrm{CXCR} 4^{+}$remained as an independent prognostic factor for significantly poorer OS $(P=.02)$ and PFS $(P=.03)$ in the overall DLBCL; However, only in GCB- but not in ABC-DLBCL patients, $\mathrm{CXCR}^{+}$expression was as an independent prognostic factor for poorer PFS $(P=.025)$. Interestingly, only in patients with $\mathrm{ABC}-\mathrm{DLBCL}$ was $\mathrm{CXCR} 4^{+}$expression associated with wide-type (WT) p53 expression in the study cohort (Supplemental Figure 1E, Table 2).

International Prognostic Index (IPI) score appeared to be a determinant of CXCR4 prognostic significance.
Only in patients with an IPI $\leq 2$ was $\mathrm{CXCR} 4^{+}$expression associated with significantly poorer OS (Figure $1 \mathrm{~N}$ ) and PFS $(P=.0002)$. In patients with an IPI $>2$, CXCR $4^{+}$ expression did not have distinguishable prognostic significance (OS, $P=.88$, Figure 1O; PFS, $P=.91$ ).

Since CXCL12 gradients differ in lymph nodes, $\mathrm{BM}$, and other tissues affecting chemotaxis, we analyzed the prognostic impact of CXCR4 expression in lymph nodes and extranodal sites separately (Figures 2A-B showed CXCR4 cell surface expression and CXCL12 mRNA levels in nodal vs primary extranodal patients). Although CXCR4 cell surface expression invariably correlated with lower CXCL12 mRNA levels in both nodal and extranodal sites (Figure 2C), CXCR4 ${ }^{+}$ expression correlated with significantly poorer OS and PFS only in nodal DLBCLs (Figures 2E-H) regardless of extranodal involvement status (Supplemental Figure 1F). In contrast, CXCR4 surface expression was negatively correlated with CXCL12 mRNA levels only in patients without BM involvement (Figure 2D). However, the prognostic significance of CXCR4 in nodal DLBCL was demonstrated in both groups either with or without $\mathrm{BM}$ involvement at diagnosis (Figures 2I-L). Together, these data suggested that the prognostic significance of CXCR4 expression is independent of BM or extranodal involvement, and reduction of CXCL12 mRNA levels in the primary sites.

\section{Association and synergy among CXCR4, Bcl-2, and Myc expression in GCB-DLBCL}

CXCR4, Myc and Bcl-2 expression showed association in both the GCB and $\mathrm{ABC}$ subtypes (Figures $3 \mathrm{~A}-\mathrm{H})$. Myc and Bcl-2 expression, and MYC and BCL2 translocation have been correlated with poor clinical outcomes [38-40]. We therefore assessed the dependency and synergism among the prognostic impact of CXCR4, Myc, and Bcl-2 expression.

Although the inverse correlation between CXCR4 surface expression and CXCL12 mRNA levels was 
independent of Bcl-2/Myc expression status (Supplemental Figures 3A-D), $\mathrm{CXCR}^{+}$expression correlated with significantly poorer survival in patients with $\mathrm{Bcl}-2^{+} \mathrm{GCB}-$ DLBCL (Figures 3I-J) or Bcl-2- ABC-DLBCL, but not in patients with Bcl-2- GCB-DLBCL or Bcl-2+ ABC-DLBCL (Supplemental Figure 2). Within the GCB-DLBCL group, in which $\mathrm{CXCR} 4^{+}$and $B C L 2$ translocations are prognostic [40], CXCR4 expression showed remarkable synergism with BCL2 translocations (Figures $3 \mathrm{~K}-\mathrm{L}$ ), in a manner no less significant than the synergism between $M Y C$ and $B C L 2$ translocations (Figure 3M).

Similarly, CXCR4 expression was synergistic with Myc overexpression (Figure $3 \mathrm{~N}$ ); however, when the group was classified into GCB and ABC subtypes, this result did not remain statistically significant (Supplemental Figures 1G-J).

Among $\mathrm{Myc}^{+} / \mathrm{Bcl}^{-} 2^{+}$patients, CXCR4 expression had an additive adverse impact in patients with GCBDLBCL (Figures 3O-P, $P=.08$ for OS and $P=.06$ for PFS), but this impact was not statistically significant in patients with ABC-DLBCL (Supplemental Figures 1K-L).

A

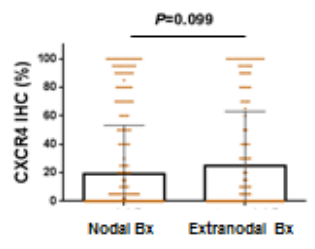

$\mathbf{E}$

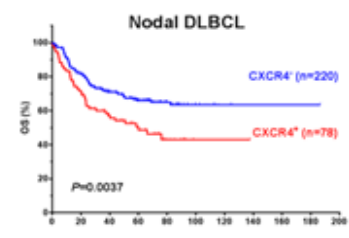

$\mathbf{F}$

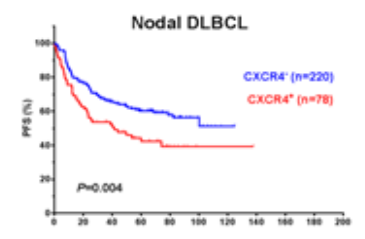

Months
B

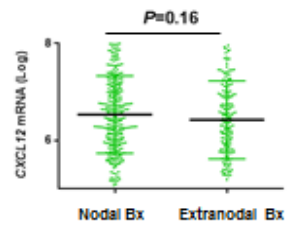

G

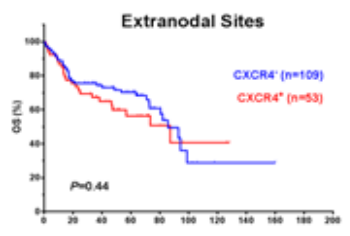

H

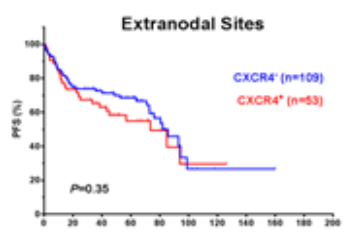

Months

\section{Association of CXCR4 expression with TP53} mutations in GCB-DLBCL

In $\mathrm{CXCR}^{+} \mathrm{GCB}-\mathrm{DLBCL}$, the frequency of TP53 mutations (which correlated with poor clinical outcomes [41]) was much higher than in CXCR4- GCB-DLBCL (38.3\% vs 21.3\%, $P=.017$, Table 2). However, the adverse impact of CXCR4 expression was independent of TP53 mutations (Supplemental Figure 3G-H). Conversely, patients with mutated (MUT)-p53 expressed higher CXCR4 levels and lower CXCL12 mRNA levels than patients with WT-p53, with significant $P$ values within the GCB subtype (Figures 4A-C).

Blimp-1 was another tumor suppressor that was significantly downregulated in $\mathrm{CXCR}^{+} \mathrm{GCB}-$ DLBCL (Figures 4D-E), and this downregulation may also contribute to the prognostic impact of CXCR4 overexpression.

\section{Multivariate survival analysis of CXCR4, Myc, Bcl-2, and TP53 mutations}

Since CXCR4 expression was associated with Myc/ Bcl-2 expression and TP53 mutations, all of which are adverse prognostic factors, multivariate survival analysis
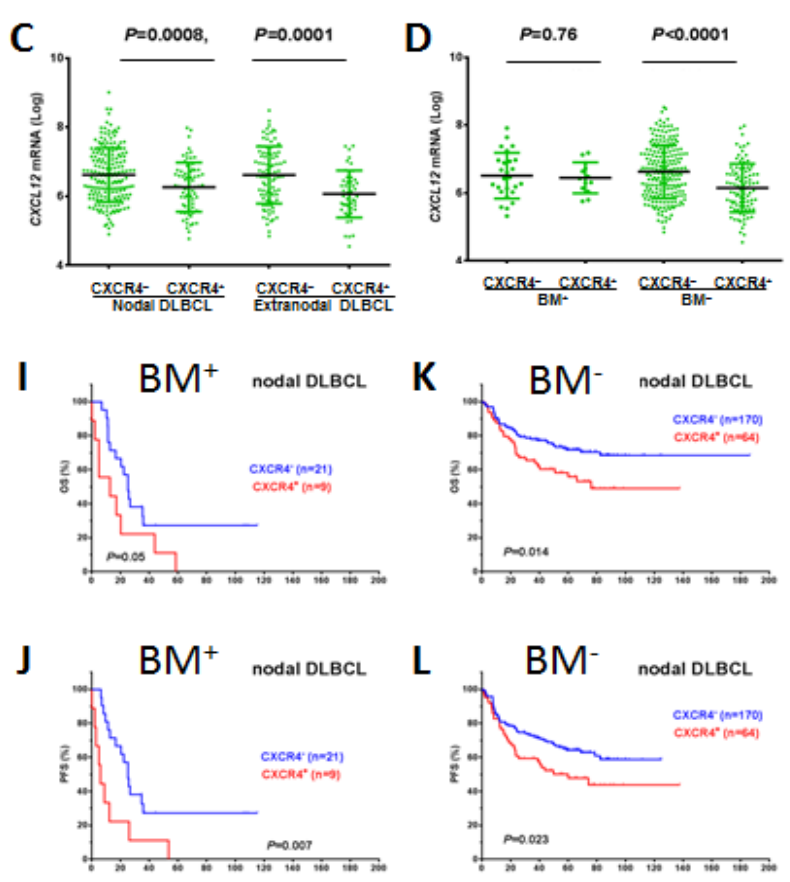

Months

Months

Figure 2: Expression and prognostic significance of CXCR4 in nodal and extranodal DLBCL. (A-B) CXCR4 cell surface and CXCL12 mRNA expression levels in nodal and extranodal DLBCL. (C) CXCR4 cell surface expression correlated with decreased CXCL12 mRNA levels, both in nodal and extranodal DLBCL. (D) CXCR4 cell surface expression correlated with decreased CXCL12 mRNA levels in DLBCL patients without bone marrow (BM) involvement. (E-F) CXCR4 expression correlated with significantly poorer OS and PFS in the nodal DLBCL. (G-H) CXCR4 expression in extranodal sites did not correlate with survival significantly in DLBCL. (I-L) the prognostic significance of CXCR4 expression was independent of BM involvement. 
Table 3: Multivariate survival analysis [Gender, IPI (age, stage, LDH, ECOG, number of extranodal sites), tumor size, B-symptoms, CXCR4, Myc, Bcl-2, and p53 expression]

\begin{tabular}{|c|c|c|c|c|c|c|}
\hline \multirow[b]{2}{*}{ Variables } & \multicolumn{3}{|c|}{ os } & \multicolumn{3}{|c|}{ PFS } \\
\hline & HR & $95 \% \mathrm{Cl}$ & $P$ & HR & $95 \% \mathrm{Cl}$ & $P$ \\
\hline \multicolumn{7}{|c|}{ Overall DLBCL } \\
\hline $\mathrm{IPI}>2$ & 2.33 & $1.70-3.21$ & $<.0001$ & 2.13 & $1.58-2.88$ & $<.0001$ \\
\hline $\mathrm{CXCR4}^{+}$ & 1.12 & $.79-1.69$ & .27 & 1. 56 & $1.13-2.46$ & .008 \\
\hline $\mathrm{Myc}^{+}$ & 2.21 & $1.55-3.14$ & $<.0001$ & 2.11 & $1.51-2.94$ & $<.0001$ \\
\hline $\mathrm{Bcl}-2^{+}$ & 1.48 & $1.04-2.10$ & .028 & 1.27 & $.94-2.10$ & .028 \\
\hline $\begin{array}{l}\text { TP53 } \\
\text { mutations }\end{array}$ & 1.66 & $1.11-2.51$ & .013 & 1. 07 & $1.17-2.46$ & .005 \\
\hline${\mathrm{p} 53^{+}}^{+}$ & 1.21 & $.84-1.75$ & .30 & 1.17 & $.83-1.66$ & .38 \\
\hline Female & .88 & $.62-1.25$ & .48 & .93 & $.67-1.30$ & .68 \\
\hline$>5 \mathrm{~cm}$ tumor & 1.24 & $.91-1.69$ & .18 & 1.16 & $.87-1.55$ & .33 \\
\hline B-symptoms & 1.36 & $.99-1.87$ & .06 & 1.32 & $.98-1.79$ & .07 \\
\hline \multicolumn{7}{|l|}{ GCB-DLBCL } \\
\hline $\mathrm{IPI}>2$ & 3.66 & $2.09-6.38$ & $<.0001$ & 3.95 & $2.40-6.50$ & $<.0001$ \\
\hline $\mathrm{CXCR4}^{+}$ & 1.35 & $.74-2.46$ & .33 & 1.75 & $1.02-3.01$ & .04 \\
\hline $\mathrm{Myc}^{+}$ & 2.83 & $1.57-5.10$ & .0001 & 2.39 & $1.43-4.00$ & .0001 \\
\hline${\mathrm{Bcl}-2^{+}}^{+}$ & 2.00 & $.96-3.90$ & .06 & 1.73 & $.94-3.19$ & .08 \\
\hline $\begin{array}{l}\text { TP53 } \\
\text { mutations }\end{array}$ & 1.48 & $.79-2.77$ & .21 & 1.74 & $1.03-2.94$ & .04 \\
\hline Female & .82 & $.47-1.43$ & .49 & .90 & $.54-1.50$ & .69 \\
\hline$>5 \mathrm{~cm}$ tumor & 1.59 & $.92-2.74$ & .097 & 1.53 & $.93-2.53$ & .096 \\
\hline B-symptoms & 1.72 & $.99-3.00$ & .05 & 1.52 & $.90-2.54$ & .12 \\
\hline \multicolumn{7}{|l|}{ ABC-DLBCL } \\
\hline $\mid \mathrm{PI}>2$ & 2.85 & $1.76-4.64$ & $<.0001$ & 2.33 & $1.47-3.68$ & $<.0001$ \\
\hline $\mathrm{CXCR}^{+}$ & 1. 32 & $.77-1.25$ & .32 & 1. 65 & $.86-2.80$ & .14 \\
\hline $\mathrm{Myc}^{+}$ & 1.47 & $.90-2.38$ & .11 & 1.48 & $.94-2.33$ & .09 \\
\hline${\mathrm{Bcl}-2^{+}}^{+}$ & 2.43 & $1.33-4.45$ & .004 & 2.21 & $1.26-3.88$ & .006 \\
\hline $\begin{array}{l}\text { TP53 } \\
\text { mutations }\end{array}$ & 2.00 & $1.07-3.71$ & .029 & 1.80 & $.95-3.36$ & .06 \\
\hline Female & .70 & $.42-1.18$ & .18 & .72 & $.43-1.31$ & .21 \\
\hline$>5 \mathrm{~cm}$ tumor & 1.12 & $.67-1.88$ & .66 & .95 & $.56-1.60$ & .83 \\
\hline B-symptoms & 1.76 & $1.05-2.93$ & .031 & 1.49 & $.89-2.52$ & .13 \\
\hline
\end{tabular}

Abbreviations: OS, overall survival; PFS, progression-free survival; HR, hazard ratio; $\mathrm{Cl}$, confidence interval; IPI, International Prognostic Index. 
Table 4: Up- and down-regulated genes in patients with $\mathrm{CXCR4}^{+}$and $\mathrm{CXCR4}^{-}$expression in overall DLBCL (false discovery rate [FDR] threshold: .01; $P$ value cutoff: .000098 ; fold change cutoff: 1.41), GCB-DLBCL (FDR threshold: .10, $P$ value cutoff: .000156 ), and ABC-DLBCL (FDR threshold: .05, $P$ value cutoff: .000109).

\begin{tabular}{|c|c|c|c|c|c|c|}
\hline \multicolumn{7}{|c|}{$\mathrm{CXCR}^{+}$vs. CXCR4 $4^{-}$} \\
\hline & \multicolumn{2}{|l|}{ DLBCL } & \multicolumn{2}{|l|}{ GCB-DLBCL } & \multicolumn{2}{|l|}{ ABC-DLBCL } \\
\hline & Upregulated & Downregulated & Upregulated & Downregulated & Upregulated & Downregulated \\
\hline $\begin{array}{l}\text { Signaling, ion } \\
\text { channels }\end{array}$ & $\begin{array}{l}\text { CXCR4, SFN, } \\
\text { TMC5 }\end{array}$ & $\begin{array}{l}\text { DUSP4, GIMAP7, } \\
\text { CSF2RB, CECR1 }\end{array}$ & $\begin{array}{l}\text { CNR1, TMC5, } \\
\text { STIM2, DOK5, } \\
\text { PTHLH }\end{array}$ & $\begin{array}{l}\text { GABBR1, } \\
\text { UBD, } \\
\text { DUSP4, } \\
\text { FYB, } \\
\text { PTPN6, } \\
\text { LAMP1, } \\
\text { NTNG2, } \\
\text { RASA3 }\end{array}$ & YTHDF2 & $\begin{array}{l}\text { FYN, FYB, } \\
\text { PBXIP1, } \\
\text { MS4A6A, } \\
\text { PLCD1, } \\
\text { ACVRL1, } \\
\text { ADAP2 }\end{array}$ \\
\hline $\begin{array}{l}\text { Cytokine, } \\
\text { chemokine }\end{array}$ & & CXCL12, CCL2 & & & & $\begin{array}{l}\text { CXCL12, } \\
\text { TNFSF12 }\end{array}$ \\
\hline $\begin{array}{l}\text { Immune } \\
\text { responses, } \\
\text { inflammation }\end{array}$ & IRF4, TCF4 & $\begin{array}{l}\text { HLA-DQA1/HLA- } \\
\text { DQA2, HLA- } \\
\text { DRB1/HLA- } \\
\text { DRB4, TRBC1, } \\
\text { GIMAP1, FYN, } \\
\text { FYB, LCP2, } \\
\text { CD3E, SIRPG, } \\
\text { SAMHD1, C3, } \\
\text { LAT }\end{array}$ & POU2AF1 & $\begin{array}{l}\text { LCP2, } \\
\text { LILRB2, } \\
\text { SAMHD1, } \\
\text { HLA-E }\end{array}$ & & $\begin{array}{l}\text { TRBC1, STAT4, } \\
\text { C2, LST1 }\end{array}$ \\
\hline $\begin{array}{l}\text { DNA } \\
\text { recombination, } \\
\text { mitotic regulation }\end{array}$ & $\begin{array}{l}\text { AICDA, } \\
\text { HELLS, ZWINT }\end{array}$ & & $\begin{array}{l}\text { MLLT11, } \\
\text { SGOL2, FRY }\end{array}$ & & $\begin{array}{l}\text { AICDA, } \\
\text { HELLS, ANLN, } \\
\text { CCDC52, } \\
\text { CDK2, } \\
\text { CEP152, } \\
\text { RAD54B }\end{array}$ & \\
\hline $\begin{array}{l}\text { Transcription } \\
\text { regulation }\end{array}$ & $\begin{array}{l}\text { FOXP1, } \\
\text { CDCA7, AFF3 }\end{array}$ & $B C L 11 B$ & & $M K L 1$ & MYEF2 & $\begin{array}{l}\text { BCL11B, } \\
\text { TXNIP, CTBP2 }\end{array}$ \\
\hline $\begin{array}{l}\text { mRNA editing, } \\
\text { translation }\end{array}$ & & $A D A R B 1$ & HRSP12 & & FARSA & SAMD $4 A$ \\
\hline Metabolism & $\begin{array}{l}\text { TMEM97, } \\
\text { FAM72A }\end{array}$ & & PTPLAD1 & $\begin{array}{l}\text { RGL1, } \\
\text { CYP46A1 }\end{array}$ & $\begin{array}{l}\text { HILPDA, } \\
\text { CYP51A1, } \\
\text { MOCOS }\end{array}$ & $\begin{array}{l}\text { SULT1A3/ } \\
\text { SULT1A4, } \\
\text { SULT1A2 }\end{array}$ \\
\hline $\begin{array}{l}\text { Transport, protein } \\
\text { modification, } \\
\text { folding, } \\
\text { chaperone, } \\
\text { degradation }\end{array}$ & DNAJC6 & RTN1, PADI2 & $\begin{array}{l}\text { TCL1A, } \\
\text { DNAJC6, } \\
\text { AP4S1 }\end{array}$ & $\begin{array}{l}\text { RTN1, } \\
\text { APOL3, } \\
\text { PARP14, } \\
\text { PSAP, } \\
\text { NAGA, } \\
\text { CYLD }\end{array}$ & SUGT1 & $\begin{array}{l}\text { FOLR2, } \\
\text { SLC46A1, } \\
\text { SLC7A6OS, } \\
\text { MARCH2 }\end{array}$ \\
\hline $\begin{array}{l}\text { Cell adhesion, } \\
\text { cytoskeleton, } \\
\text { collagen, } \\
\text { extracelluar matrix }\end{array}$ & & $\begin{array}{l}\text { DPT, EPB41L2, } \\
\text { ITGB2, UTRN } \\
\text { SH3KBP1 }\end{array}$ & EML6, STK33 & $\begin{array}{l}\text { ITGB2, } \\
\text { MYO1F }\end{array}$ & $\begin{array}{l}\text { FLJ23834, } \\
\text { TTC30A, } \\
\text { NPHP1 }\end{array}$ & $\begin{array}{l}\text { MFAP4, ITGAL, } \\
\text { EVL, CD6, } \\
\text { FGD3, } \\
\text { SIGLEC7 }\end{array}$ \\
\hline $\begin{array}{l}\text { Differentiation, } \\
\text { development }\end{array}$ & & ITM2A, SLAMF8 & & SLFN5 & $\begin{array}{l}\text { FIGNL1, } \\
\text { DAZAP1 }\end{array}$ & TMEM2 \\
\hline $\begin{array}{l}\text { Apoptosis, } \\
\text { autophage }\end{array}$ & PEG10 & MAF, RASSF4 & & $\begin{array}{l}\text { RASSF } 4 \\
\text { GIMAP5 }\end{array}$ & $\begin{array}{l}\text { PEG10, PIM2, } \\
\text { BECN1 }\end{array}$ & TBRG1 \\
\hline $\begin{array}{l}\text { IncRNA genes, } \\
\text { unknown function }\end{array}$ & $\begin{array}{l}\text { RNF183, } \\
\text { P704P, } \\
\text { C13orf18, } \\
\text { FAM129C, } \\
\text { KLHL23 } \\
\end{array}$ & $\begin{array}{l}\text { C16orf54, } \\
\text { EPSTI1 }\end{array}$ & $\begin{array}{l}\text { TCL6, ST7OT4, } \\
\text { LOC100131683 }\end{array}$ & $\begin{array}{l}\text { C6orf204, } \\
\text { FAM105A }\end{array}$ & $\begin{array}{l}\text { DPY19L2P2, } \\
\text { C9orf40, } \\
\text { CCDC117 }\end{array}$ & $\begin{array}{l}\text { LOC100131096, } \\
\text { LOC400236, } \\
\text { LOC646014, } \\
\text { GDPD3, } \\
\text { N4BP2L1 }\end{array}$ \\
\hline
\end{tabular}


of the pathological factors (including $\mathrm{CXCR} 4^{+}, \mathrm{Myc}^{+}$, Bcl-2 ${ }^{+}$and TP53 mutations) and the clinical parameters (including IPI, gender, tumor size, and B symptoms) was performed, which indicated CXCR4 was an independent prognostic factor for disease progression (hazard ratio $1.56,95 \%$ confidence interval of rate $1.13-2.46, P=.008$. Table 3).

However, when dissected in the GCB and $\mathrm{ABC}$ subtypes, the independent prognostic significance of $\mathrm{CXCR}^{+}{ }^{+}$was limited to GCB-DLBCL $(P=.04$ for PFS); in ABC-DLBCL, Myc and Bcl-2 overexpression and TP53 mutations but not CXCR4 expression, independently predicted poorer survival (Table 3 ).

We validated the prognostic significance of CXCR4 in an independent DLBCL cohort $(n=275)$ and confirmed that the prognostic significance of CXCR4 was most common in patients with an IPI $\leq 2$, depended on Bcl-2 overexpression in GCB-DLBCL, and had synergy with

A

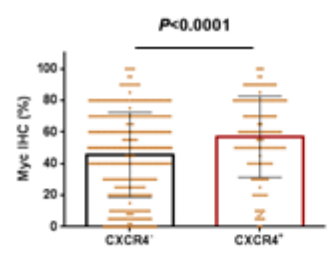

\section{E}

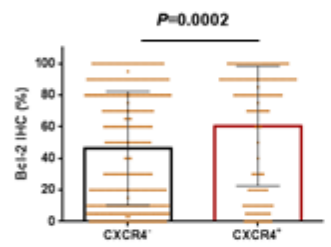

I

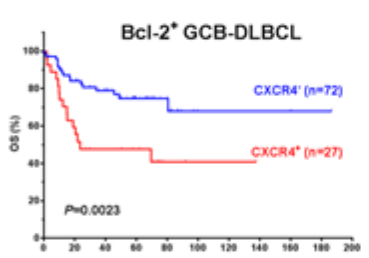

J

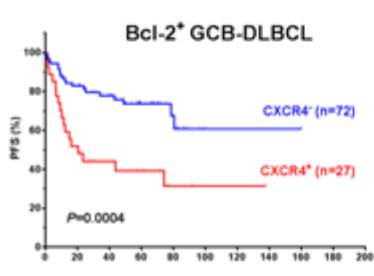

Months
B
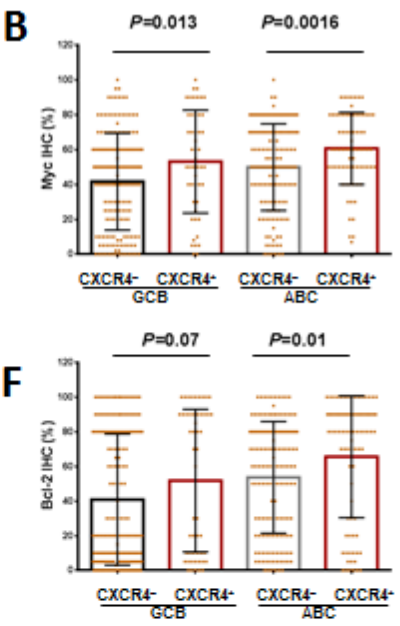

$\mathbf{K}$

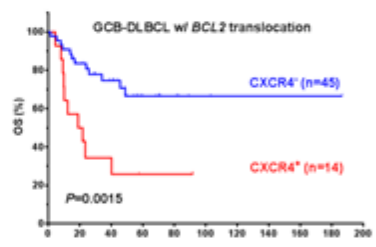

$\mathbf{L}$

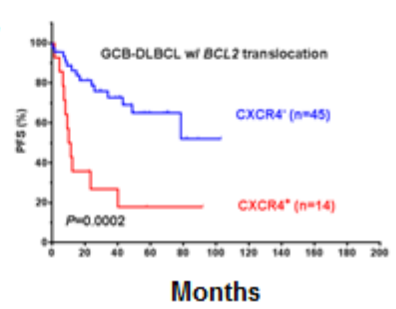

Myc expression (Supplemental Figure 4).

\section{Differentially expressed genes in $\mathrm{CXCR}^{+}$versus CXCR4- DLBCL patients}

We compared the GEP of CXCR4 ${ }^{+}$and $\mathrm{CXCR} 4^{-}$ DLBCLs, and found that 447 genes were significantly differentially expressed with a false discovery rate (FDR) threshold .01 and a fold change cutoff of over 1.41 (Table 4). Likely owing to the significantly reduced CXCL12 expression, which facilitates T cell infiltration and trafficking, the GEP of patients with $\mathrm{CXCR}^{+}$ DLBCL revealed remarkably lower expression of T-cell and innate immune response biomarkers (MHC class II molecules HLA-DQA1/HLA-DQA2, HLA-DRB1/HLADRB4, TRBC1, GIMAP1, FYN, FYB, LCP2, CD3E, SIRPG, C3, LAT, MAF, and SAMHD1 involved in antigen presentation and $\mathrm{T}$ cell signaling) indicating worse

C

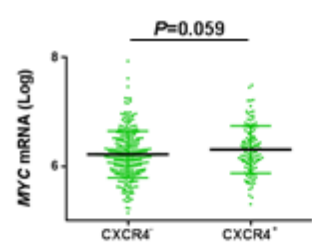

G

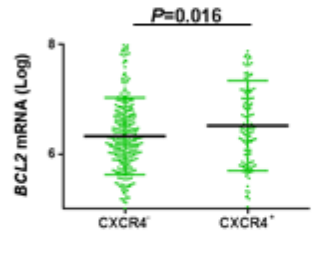

D

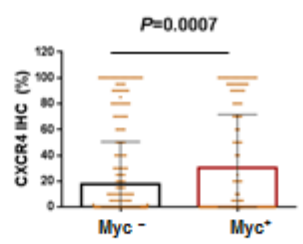

H

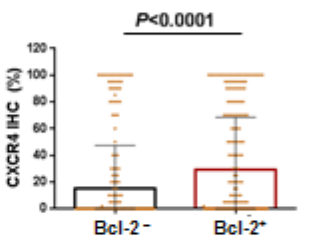

M

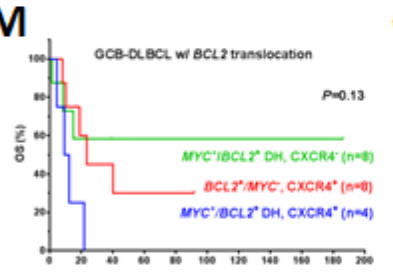

N

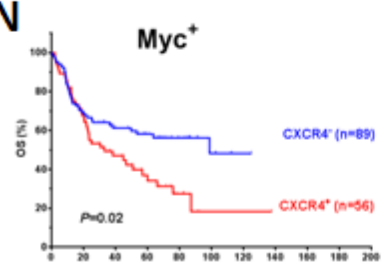

Months
0

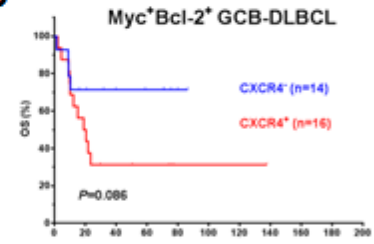

$\mathbf{P}$

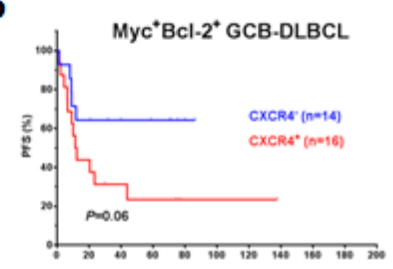

Months

Figure 3: Association of CXCR4 expression with $\mathrm{Myc} / \mathrm{Bcl}-2$ expression and the synergism of prognostic significance in DLBCL. (A-D) Association between CXCR4 and Myc expression levels. (E-H) Association between CXCR4 and Bcl-2 expression levels. (I-J) CXCR4 expression synergized with Bcl-2 expression in GCB-DLBCL. (K-L) CXCR4 expression synergized with BCL2 translocation in GCB-DLBCL. (M) The synergism between BCL2 translocation and CXCR4 expression was independent of double-hit MYC/BCL2 translocations. (N) CXCR4 expression synergized with Myc expression in DLBCL. (O-P) the prognostic significance of CXCR4 in GCB-DLBCL patients with concurrent Myc/Bcl-2 expression. 
Table 5: Up- and down-regulated genes in DLBCL patients with $\mathrm{CXCR}^{+}$and $\mathrm{CXCR}^{-}$expression and an IPI $\leq 2$ (false discovery rate threshold: .01; $P$ value cutoff: .000058 ; fold change cutoff:

1.57).

\begin{tabular}{|c|c|c|}
\hline & $\mathrm{CXCR4}^{+}$vs. CXCR4' DLBCL & with an $|P| \leq 2$ \\
\hline & Upregulated & Downregulated \\
\hline Signaling, ion channels & & GIMAP2 \\
\hline Cytokine, chemokine & & CXCL12 \\
\hline Immune responses, inflammation & & $\begin{array}{l}\text { SIRPG, TRBC1, LAT, FYB, FYN, } \\
\text { LCP2, GVIN1, HLA-DQA1/ HLA-DQA2, } \\
\text { HLA-DRB1/HLA-DRB4, }\end{array}$ \\
\hline DNA recombination, mitotic regulation & AICDA, HELLS, ZWINT & \\
\hline Transcription regulation & $C D C A 7, A F F 3$ & BCL11B, TXNIP \\
\hline mRNA editing, translation & & $A D A R B 1$ \\
\hline Metabolism & FAM72A & \\
\hline $\begin{array}{l}\text { Transport, protein modification, folding, } \\
\text { chaperone, degradation }\end{array}$ & AP1S3 & SPNS1, APOC1, RTN1 \\
\hline \multicolumn{3}{|l|}{$\begin{array}{l}\text { Cell adhesion, cytoskeleton, collagen, } \\
\text { extracelluar matrix }\end{array}$} \\
\hline Differentiation, development & & ITM2A, SLAMF8 \\
\hline Apoptosis, autophage & RASSF6, PEG10 & MAF, RASSF4 \\
\hline IncRNA genes, unknown function & $\begin{array}{l}\text { C13orf18, FAM129C, RNF183, } \\
\text { KLHL23, DPY19L2P2 }\end{array}$ & \\
\hline
\end{tabular}

prognosis [42], and cell adhesion genes. In addition, CXCR4 gene signatures also included upregulated survival genes and downregulated pro-apoptosis genes in CXCR4 $4^{+}$tumor cells. Upregulated genes included $S F N$ (2.57 fold) which stimulates the Akt/mTOR pathway, HELLS which is involved in lymphoid cell survival (1.55 fold), Myc-responsive gene $C D C A 7$ which contributes to the Myc-mediated tumorigenesis (1.51 fold), oncogenic transcription factor $A F F 3$ (1.45 fold), FAM72A which regulates cell growth (1.44 fold), and antipoptotic $P E G 10$ (1.85 fold). In contrast, pro-apoptotic RASSF4 was downregulated (1.42 fold). AICDA, encoding activationinduced cytidine deaminase which mediates somatic hypermutation and class-switch recombination, was upregulated by 2.92 fold in patients with CXCR4 $4^{+}$DLBCL (3.32 fold in ABC-DLBCL and 2.12 fold in GCB-DLBCL, Figures 4F-G). Furthermore, these signatures largely overlapped the differentially expressed genes (DEGs) identified between CXCR4 ${ }^{+}$and CXCR4- DLBCL patients with an IPI $\leq 2$ (Supplemental Figure 3I and Table 5), whereas no DEGs were identified between $\mathrm{CXCR}^{+}$and CXCR4- DLBCLs with an IPI $>2$.

GCB-DLBCL and ABC-DLBCL have distinct molecular programs, therefore, CXCR4 expression signatures were further identified in the GCB and ABC subsets separately (Figures $4 \mathrm{H}-\mathrm{I}$ and Table 4). The immunosuppressive, proliferative, and antiapoptotic CXCR4 signatures were observed in both GCB and $\mathrm{ABC}$ subtypes. In GCB-DLBCL, downregulation of $F Y B, L C P 2$, $L I L R B 2, S A M H D 1$, and $H L A-E$, suggested decreased adaptive and innate immune responses. In ABC-DLBCL, downregulation of FYN, FYB, TRBC1, STAT4, C2, and $L S T 1$, suggested decreased adaptive immune responses. In $\mathrm{ABC}-\mathrm{DLBCL}$, the proliferation and antiapoptotic CXCR4 
signatures were remarkable, such as upregulation of genes involved in the cell cycle progression, mitosis, translation, metabolism and antiapoptosis (including CDK2, HELLS, CCDC52, FARSA, hypoxia-inducible lipid-dropletassociated protein [HILPDA], PEG10, PIM2, and $B E C N 1$ ), and downregulation of the MTORC1 inhibitor $T X N I P$, the tumor suppressors BCL11B and TBRG1. The involvement of the Myc and TP53 pathways in the CXCR4 signaling was suggested by the upregulation of PIM2, which increases Myc stability and transcriptional activity, and the downregulation of BCL11B and TBRG1, which activate p53.

Many genes were differentially regulated in GCB and $\mathrm{ABC}$ subtypes, including the ones involved in the PI3K pathway (Figures 4J-L), MAPK signaling, NF- $\kappa B$ and angiogenesis (Table 4). In GCB-DLBCL, positive regulation of the MAPK pathway by $\mathrm{CXCR} 4$ expression was suggested by the upregulation of DOK5, PTHLH (which transports calcium), and STIM2 (which activates $\mathrm{Ca}^{2+}$ entry channels) and the downregulation of its negative regulator DUSP4. In contrast, in ABC-DLBCL, negative regulation of MAPK by CXCR4 signaling was indicated by the downregulation of FYN upstream of the MAPK signaling pathway, and the downregulation of calcium-dependent molecules such as MFAP4. In the GCB subtype, $C Y L D$ and $U B D$ which activate NF- $\kappa \mathrm{B}$
A

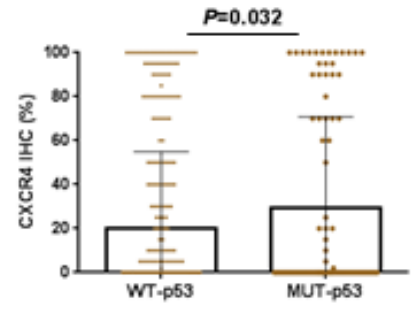

D
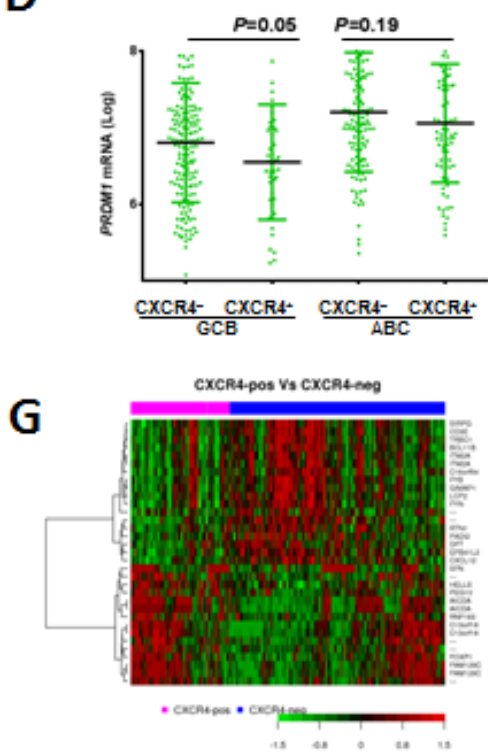

J

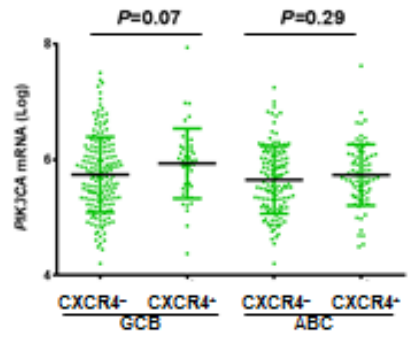

B

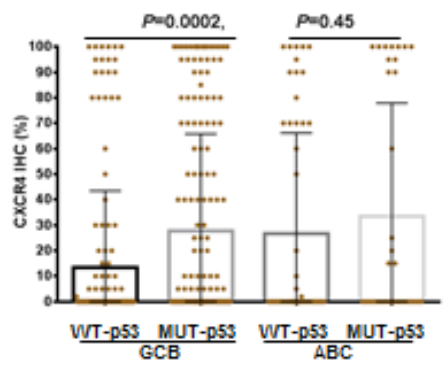

E

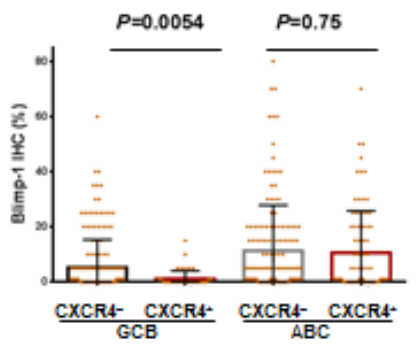

H

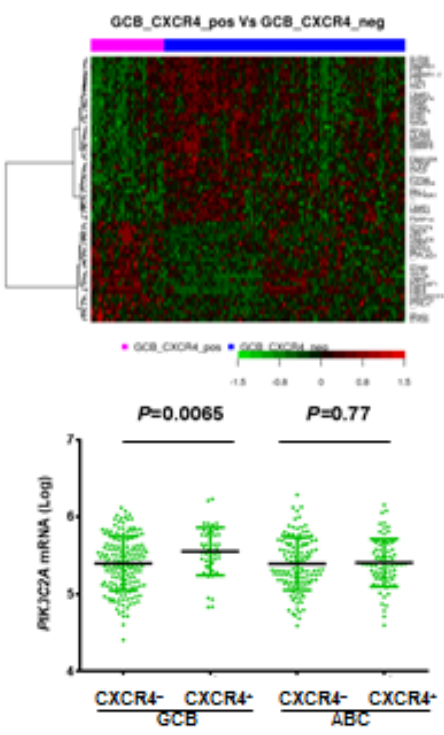

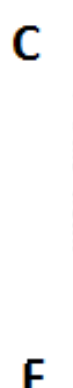

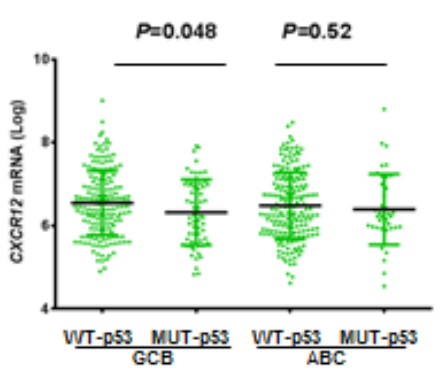

$\mathbf{F}$
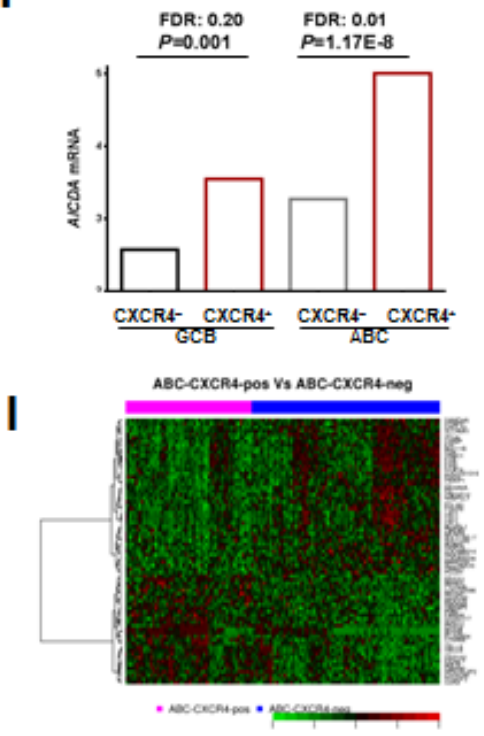

L

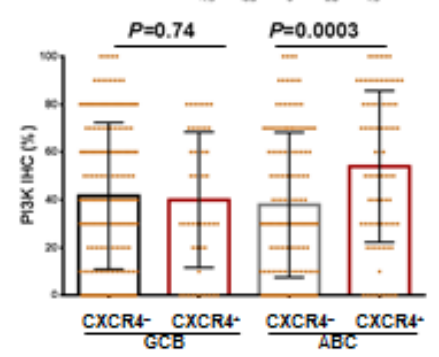

Figure 4: Regulation of and signaling pathways related to CXCR4 expression. (A-C) p53 mutations were associated increased CXCR4 and decreased CXCL12 mRNA expression, especially in GCB-DLBCL. (D-E) CXCR4 expression was associated with decreased PRDM1 mRNA and BLIMP-1 expression in GCB-DLBCL. (F) CXCR4 expression was associated with increased AICDA mRNA expression both in GCB- and ABC-DLBCL. (G-H) Heatmaps and differentially expressed genes between CXCR4 $4^{+}$and CXCR4- patients in the overall DLBCL, GCB-DLBCL and ABC-DLBCL cohorts. (J-K) CXCR4 expression was associated with increased PI3K mRNA expression in GCB-DLBCL, and increased protein expression in ABC-DLBCL. 
were downregulated in $\mathrm{CXCR} 4^{+}$compared to $\mathrm{CXCR} 4$ DLBCL patients. In the ABC subtype, NF- $\mathrm{B}$ pathway showed opposite regulations: $\mathrm{NF}-\kappa \mathrm{B}$ activators $C A R D 11$ and PIM2 were upregulated, whereas TNFSF 12, TNFSF8 and $I L 12 R B$ were downregulated (Figure 4I, Supplemental Figures 3J-L). In CXCR4 ${ }^{+}$GCB-DLBCL, PTPN6/PTN6 which modulates epidermal growth factor receptor was downregulated whereas in $\mathrm{CXCR}^{+} \mathrm{ABC}-\mathrm{DLBCL}$, HILPDA which activates vascular endothelial growth factor A was upregulated.

Pathway analysis (http://www.qiagen.com/ ingenuity) indicated CXCR4 signatures were associated with functional networks of cell-to-cell signaling and interaction, immune cell trafficking, hematological system development and function, cellular growth and proliferation, cell death and survival (Supplemental Figure 5).

A

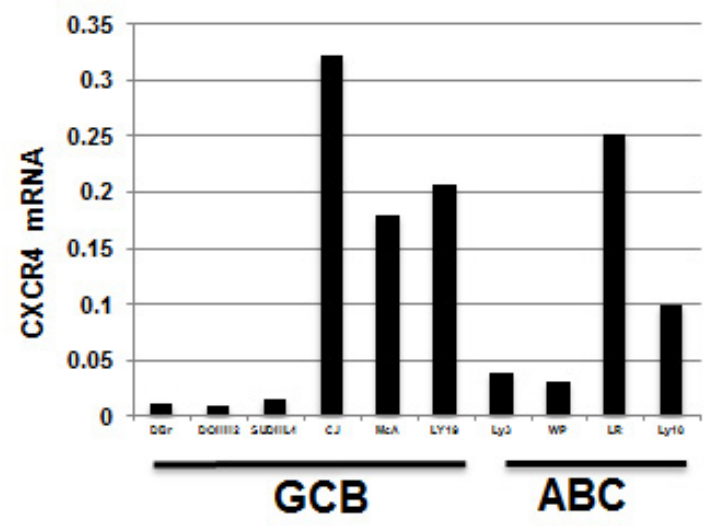

\section{Effect of CXCR4 inhibitor BKT140 on the growth of DLBCL cells}

We assessed the effect of the CXCR4 inhibitor BTK140 on growth of DLBCL cells. In 10 cell lines of either the GCB or ABC subtype, BKT140 treatment resulted in a significant dose-dependent growth inhibition in all 10 cell lines, with half maximal inhibitory concentration values ranging from 16.55 to $79.33 \mathrm{nM}$; however, the inhibition did not appear to depend on CXCR4 expression (Figure 5A-B). BTK140 indeed inhibit CXCR4-mediated cell adhesion, suggested by the alteration of growth patterns of DLBCL cells expressing high CXCR4 mRNA. The proliferation pattern of DLBCL cells changed from adhesive to discohesive after 48 hours of incubation with different concentrations of BKT140 (Figure 5C).

\section{B}

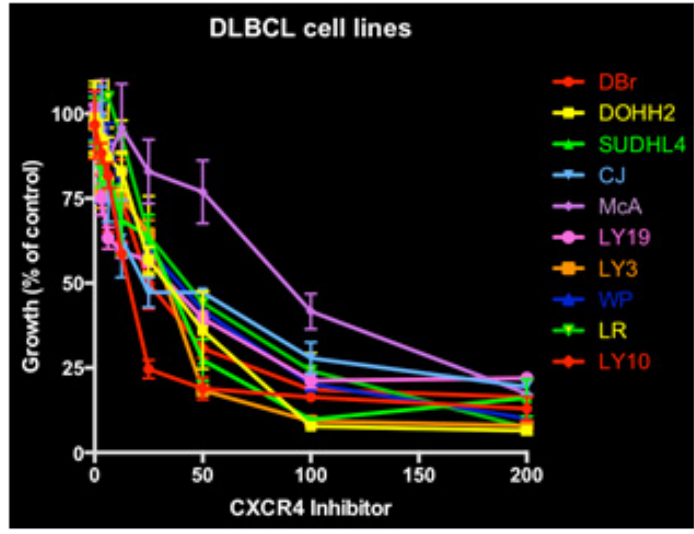

IC50 ( $\mu \mathrm{M})$

16.55

37.51

33.49

51.45

79.33

41.24

30.55

45.52

48.78

32.85

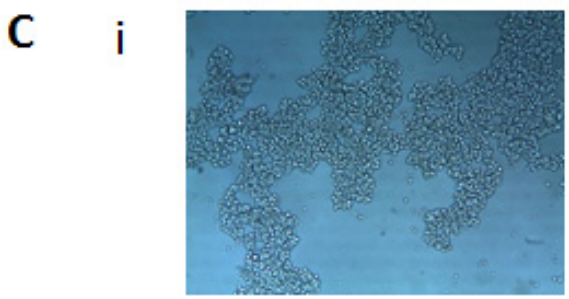

ii

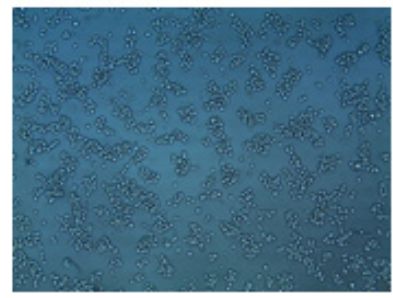

II

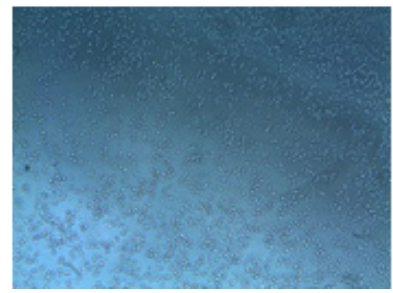

iii

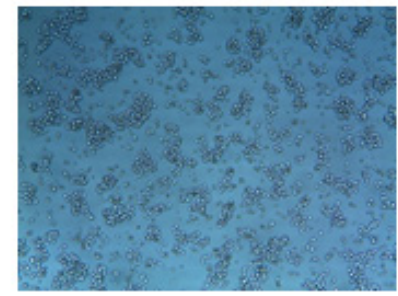

III

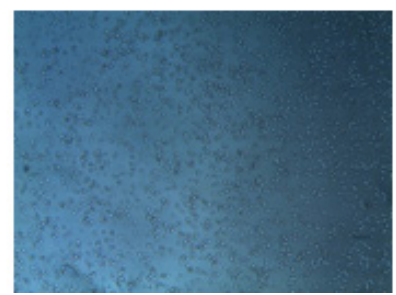

Figure 5: Effects of BTK140 on proliferation and the growth patterns of DLBCL cells. (A) Expression levels of CXCR4 mRNA in DLBCL cell lines. (B) Ten DLBCL cell lines were treated with BTK140 in a dose-dependent manner. Cell proliferation was measured using ${ }^{3} \mathrm{H}$-thymiding incorporation assay after 72 hours incubation. Dates shown are the means and ranges of triplicate samples relative to control samples of three independent experiments. (C) The proliferation pattern of McA cells incubated without BKT140 (i), with 6.25uM BKT140 (ii), and with 50uM BKT140 (iii). (C) The proliferation pattern of LY19 incubated without BKT140 (I), with 6.25uM BKT140 (II), and with 50uM BKT140 (III). 


\section{DISCUSSION}

The CXCR4/CXCL12 axis is essential for development, hematopoiesis, vascularization [4], and migration, homing and retention of stem cells. In the current study, CXCR4 expression was associated with poorer OS $(P=.0016)$ and PFS $(P=.0017)$ in a large cohort of 468 de novo DLBCL patients treated with R-CHOP (Figures 1H-I) and poorer therapy response in 236 GCB-DLBCLs. However, although univariate analysis of CXCR4 expression showed prognostic significance in both $\mathrm{GCB}$ and $\mathrm{ABC}$ subtypes, multivariate analysis indicated that $\mathrm{CXCR} 4$ expression was an independent prognostic factor for poorer PFS only in GCBDLBCL patients. Furthermore, our data suggested that concurrent CXCR4 expression and BCL2 translocation may represent another type of double-hit DLBCL with aggressive clinical courses. In ABC-DLBCL, Myc/ Bcl-2 expression and TP53 mutations but not CXCR4 expression independently predicted poor survival. The lack of independent prognostic significance of CXCR4 expression in ABC-DLBCL was likely due to the tumor suppression function of WT-p53 whose expression was associated with $\mathrm{CXCR}^{+}$in $\mathrm{ABC}$-DLBCL. It may also be attributed to the significantly $(P=.0047)$ higher proportion of patients with an IPI $>2$ in ABC (68.4\%) than in GCB (55\%), as the prognostic significance and biologic impact of CXCR4 expression was only demonstrated in patients with low-risk IPI.

It is widely accepted that the CXCR4/CXCL12 axis underlies the decreased chemosensitivity and disease progression, by directing CXCR4-expressing tumor cells through concentration gradients of CXCL12 to reside in protective niche (such as BM and lymph nodes). Our results showed that $\mathrm{CXCR} 4$ expression had a significant prognostic impact in nodal DLBCL but not extranodal DLBCL. However, only $10.7 \% \mathrm{CXCR}^{+}$patients showed $\mathrm{BM}$ involvement at diagnosis, and the adverse impact of CXCR4 expression in nodal DLBCL is independent of BM involvement, suggesting other malignant consequences besides BM homing ensuing CXCR4 expression in DLCBL. In patients without BM involvement, we surprisingly observed an inverse correlation between CXCR4 surface expression and CXCL12 mRNA expression in stromal cells. This paradoxical phenomenon was also observed in primary kidney tumor tissues [43]. We speculate that the abnormal CXCR $4^{\text {high }} / \mathrm{CXCL} 12^{\text {low }}$ condition at the primary sites lead to the dissemination of $\mathrm{CXCR}^{+}$lymphoma cells to distant organs expressing higher CXCL12, which resulted in disease progression of $\mathrm{CXCR}^{+}$DLBCL. Supporting this hypothesis, CXCL12 expression was a strong independent prognostic biomarker for better survival in breast cancers [44], and administration of CXCL12 has been suggested as a potent inhibitor of colorectal and melanoma metastasis [45]. In addition, $\mathrm{CXCR}^{+}$demonstrated different prognostic values in different disease subsets although it consistently correlated with decreased CXCL12 mRNA levels in these subsets (Figures 2, 3, Supplemental Figures 2, 3A-D). Therefore, $C X C L 12$ reduction alone may be insufficient to account for the CXCR4-associated disease progression.

Furthermore, our protein expression and GEP data suggested that the impact of CXCR4 on lymphoma relapse and progression of de novo DLBCL may be attributed to dysregulations in both the tumor microenvironment and the tumor cells themselves. These mechanisms used by CXCR4 for tumor cell survival may include reduced immune surveillance, increased tumor proliferation involving the upregulation of the Myc and PI3K/ mTOR pathways, and blocked apoptosis involving Bcl2 expression and the TP53 pathway. Previous studies showed that p53 negatively regulated expression of CXCR4 [2] (consistent with our results) and CXCL12 $[46,47]$ (inconsistent with our mRNA results) abrogating the stromal cell-mediated chemoresistance. The role of CXCR4 signaling in promoting proliferation and survival was supported by the in vitro studies, where the high-affinity CXCR4 inhibitor BTK140 alone resulted in inhibited proliferation as well as inhibitory changes of adhesion and growth patterns in various DLBCL cell lines. These novel oncogenic mechanisms, in addition to the dissemination of $\mathrm{CXCR} 4^{+}$tumor cells to distant lymphatic tissues with high CXCL12 concentrations, may synergistically account for the CXCR4-mediated disease progression.

In cancer cells, CXCR4 expression can be caused by hypoxia, NF- $\kappa \mathrm{B}$ activation, and ubiquitination inhibition [4]. In some patients of our cohort, increased CXCR4 expression may have resulted from reduced degradation, as suggested by decreased expression of $U B D /$ ubiquitin $D$ and the deubiquitinating enzyme $C Y L D$ in GCB-DLBCL and decreased E3 ubiquitin-protein ligase $M A R C H 2$ in ABC-DLBCL. In ABC-DLBCL, upregulated SUGT1, which plays a role in ubiquitination and subsequent proteasomal degradation of target proteins, may counteract the CXCR4 increase. Hypoxia (as suggested by increased $H I L P D A)$ which is known for CXCR4 activation $[3,4,9]$, may also be the causes of $\mathrm{CXCR} 4$ expression in $\mathrm{ABC}$ DLBCL.

Cell-of-origin may as well explain the $\mathrm{CXCR}^{+}$ phenotype. Some CXCR4 ${ }^{+}$GCB-DLBCLs may represent lymphoma cells arising from $\mathrm{CXCR} 4^{\text {high }}$ centroblasts in the CXCL12-rich dark zone and CXCR4- GCB-DLBCLs may be the transformed $\mathrm{CXCR} 4^{\text {low }}$ centrocytes in the light zone, where B cells interact with follicular dendritic and T helper cells. This hypothesis is in line with the higher activationinduced cytidine deaminase levels, highly proliferative characteristics, and the lack of $\mathrm{T}$ cell signature in $\mathrm{CXCR}^{+}$ patients $[23,24]$, but is contradicted by the $\mathrm{CXCR}^{+}$ associated low CXCL12 levels. A plausible explanation is that abnormal reduction in CXCL12 expression in lymph nodes (due to oncogenic mechanisms such as 
dysregulated TNF cytokines or Myc overexpression, or as the secondary event of BCL2 translocation in the GC) initiated the tumorigenesis. This was selected for CXCR4 $4^{\text {high }}$ lymphoma cells due to the dynamics of CXCL12/CXCR4 equilibrium and led to decreased T cell infiltration and deficient immune responses due to reduced chemoattraction, cooperating with the CXCR4-associated pro-survival signals. Decreased CXCL12 expression further led to dissemination of $\mathrm{CXCR}^{+}$tumor cells to distant lymphatic tissues with higher CXCL12 expression $[28,51]$. Therefore, the abnormal CXCL12/CXCR4 levels may be relevant for both lymphomagenesis and disease progression.

In conclusion, our results indicated CXCR4 expression was associated with poorer clinical outcomes in DLBCL and independently predicted disease progression in GCB-DLBCL. The underlying mechanisms whereby CXCR4 exerts its prognostic impact may include tumor growth promotion, apoptosis inhibition, decreased $\mathrm{T}$ cell infiltration and immune responses, and tumor cell dissemination to distant organs/tissues. These results could help stratify DLBCL and gain insight of molecular events that function as therapeutic targets.

\section{PATIENTS AND METHODS}

\section{Patients}

The training study consisted of 468 patients with de novo DLBCL diagnosed between 2000 and 2010 and treated with R-CHOP (median age: 63 years). The diagnostic criteria, review process, eligibility and exclusion criteria, cell-of-origin classification as either GCB or ABC subtype via GEP or IHC algorithms have been described previously $[38,41,48]$. At last followup, 176 of $468(37.6 \%)$ patients had died. The median follow-up for the 292 censored patients was 48.7 months. For validation, an independent cohort of 275 de novo DLBCLs diagnosed between 2002 and 2007 and treated with R-CHOP was used, with median follow-up of 50 months. This study was conducted in accordance with the Declaration of Helsinki and was approved as being of minimal to no risk or as exempt by the Institutional Review Boards of all participating centers, including The University of Texas MD Anderson Cancer Center.

\section{CXCR4 cell surface expression and other pathological experiments}

IHC analyses for CXCR4 expression using polyclonal anti-CXCR4 antibody (Abcam) and antihuman CXCR4 mAb (R\&D Systems) were performed on tissue microarrays of formalin-fixed, paraffin-embedded (FFPE) lymphoma samples and was assessed by three pathologists blinded from clinical outcomes with similar results. The inter-observer agreement was $98 \%$, and the disagreement was resolved by joint review at a multiheaded microscope.

IHC of other biomarkers using respective monoclonal antibodies, fluorescence in situ hybridization to detect MYC, BCL6, and BCL2 translocations, and TP53 resequencing using p53 AmpliChip have been described previously [38-41,48,49].

\section{Gene expression profiling}

GEP by the Affymetrix GeneChip Human Genome U133 Plus 2.0 array was performed using total RNAs extracted from FFPE tissues as previously described [38$41,48,49]$. Normalized microarray data were analyzed for differential gene expression between the $\mathrm{CXCR}^{+}$ and $\mathrm{CXCR}^{-}$groups. Univariate analysis using a $t$ test was performed to identify differentially expressed genes. The $P$ values obtained via multiple $t$-tests were corrected for FDRs using the beta-uniform mixture method. Differentially expressed genes were identified at various FDRs with different $P$ value cutoffs. Pathway analysis for the identified DEGs was performed using Ingenuity ${ }^{\circledR}$ Pathway Analysis (IPA ${ }^{\circledR}$, http:/wwww.qiagen.com/ ingenuity) software program.

\section{Effect of CXCR4 inhibitor BTK140 in vitro}

The inhibitory effect of BTK140 (kind gift from BioLineRx Ltd, Jerusalem, Israel) was evaluated in 10 DLBCL cell lines that were either the GCB (DBr, DOHH2, SUDHL4, CJ, McA, LY19) or ABC (LY3, WP, LR, and LY10) subtype that were cultured and maintained in RPMI 1640 (Life Technologies, Rockville, MD, USA) and $15 \%$ fetal calf serum (HyClone, Logan, UT, USA). $\left[{ }^{3} \mathrm{H}\right]$ thymidine proliferation assays in vitro were performed as described previously [50]. Different concentrations of BKT140 were used: $3.125 \mu \mathrm{M}, 6.25 \mu \mathrm{M}, 12.5 \mu \mathrm{M}, 25$ $\mu \mathrm{M}, 50 \mu \mathrm{M}, 100 \mu \mathrm{M}$, and $200 \mu \mathrm{M}$. Cell proliferation was measured using ${ }^{3} \mathrm{H}$-thymidine incorporation assays after 72 hours of incubation.

\section{Statistical analysis}

The clinicopathologic features of $\mathrm{CXCR}^{+}$and CXCR4- DLBCL patients at the time of presentation were compared using the chi-square test. Overall survival was calculated from the time of diagnosis to death from any cause or last follow-up. Progression-free survival was calculated from the time of diagnosis to disease progression, relapse, or death from any cause. ${ }^{21}$ Patients who were alive and/or had no disease progression were censored at last follow-up. Survival analysis was 
performed using the Kaplan-Meier method with GraphPad Prism 6 (GraphPad Software, San Diego, CA), and differences were compared using the log-rank (MantelCox) test. Multivariate survival analysis was performed using the Cox proportional hazards regression model with the SPSS statistics software program (version 19.0; IBM Corporation, Armonk, NY). All differences with $P \leq .05$ were considered statistically significant.

\section{ACKNOWLEDGEMENTS}

This work is supported by The University of Texas MD Anderson Cancer Center Institutional Research Grant Award, MD Anderson Lymphoma and Myeloma Specialized Programs of Research Excellence (SPORE) Research Development Program Awards, MD Anderson Collaborative Research Funds with High-Throughput Molecular Diagnostics, Gilead Pharmaceutical, and Roche Molecular Systems, and National Cancer Institute and National Institutes of Health grants (R01CA138688 and R01CA187415) to K.H.Y. This work was also partially supported by Medical School of Taizhou University Scholarship Award to J.C. QS is the recipient of MD Anderson Pathology Fellowship Award. ZYXM is the recipient of the Harold C. and Mary L. Daily Endowment Fellowships and Shannon Timmins Fellowship for Leukemia Research Award.

\section{AUTHOR CONTRIBUTIONS}

Conception and design: JC, ZYXM, KHY; Research performing: JC, ZYXM, KHY; Provision of study materials, key reagents and technology: JC, ZYXM, LD, QS, GCM, AML, LZ, SMM, CV, AZ, LZ, LY, KD, AC, AO, YZ, GB, KLR, EDH, WWLC, JHK, MP, AJF, XZ, JPF, JNW, MAP, LVP, KHY; Collection and assembly of data under approved IRB and MTA: JC, ZYXM, CV, AT, AML, SMM, KD, AC, AO, YZ, GB, KLR, EDH, WWLC, JHK, MP, AJF, XZ, JPF, JNW, MAP, KHY; Data analysis and interpretation: JC, ZYXM, KHY; Manuscript writing: JC, ZYXM, KHY; Final approval of manuscript: All authors

\section{CONFLICTS OF INTEREST DISCLOSURE}

The authors declare no conflicts of interest.

\section{REFERENCES}

1. Kallikourdis M, Trovato AE, Anselmi F, Sarukhan A, Roselli G, Tassone L, Badolato R, Viola A. The CXCR4 mutations in WHIM syndrome impair the stability of the T-cell immunologic synapse. Blood 2013; 122:666-73.

2. Mehta SA, Christopherson KW, Bhat-Nakshatri P, Goulet
RJ, Jr., Broxmeyer HE, Kopelovich L, Nakshatri H. Negative regulation of chemokine receptor CXCR4 by tumor suppressor $\mathrm{p} 53$ in breast cancer cells: implications of p53 mutation or isoform expression on breast cancer cell invasion. Oncogene 2007; 26:3329-37.

3. Cojoc M, Peitzsch C, Trautmann F, Polishchuk L, Telegeev GD, Dubrovska A. Emerging targets in cancer management: role of the CXCL12/CXCR4 axis. Onco Targets Ther 2013; 6:1347-61.

4. Busillo JM, Benovic JL. Regulation of CXCR4 signaling. Biochim Biophys Acta 2007; 1768:952-63.

5. Yoshida N, Kitayama D, Arima M, Sakamoto A, Inamine A, Watanabe-Takano H, Hatano M, Koike T, Tokuhisa T. CXCR4 expression on activated B cells is downregulated by CD63 and IL-21. J Immunol 2011; 186:2800-8.

6. Bruhl H, Cohen CD, Linder S, Kretzler M, Schlondorff D, Mack M. Post-translational and cell type-specific regulation of CXCR4 expression by cytokines. Eur J Immunol 2003; 33:3028-37.

7. Muller A, Homey B, Soto H, Ge N, Catron D, Buchanan ME, McClanahan T, Murphy E, Yuan W, Wagner SN, Barrera JL, Mohar A, Verastegui E, et al. Involvement of chemokine receptors in breast cancer metastasis. Nature 2001; 410:50-6.

8. Balkwill F. Cancer and the chemokine network. Nat Rev Cancer 2004; 4:540-50.

9. Sun X, Cheng G, Hao M, Zheng J, Zhou X, Zhang J, Taichman RS, Pienta KJ, Wang J. CXCL12 / CXCR4 / CXCR7 chemokine axis and cancer progression. Cancer Metastasis Rev 2010; 29:709-22.

10. Schimanski CC, Bahre R, Gockel I, Muller A, Frerichs K, Horner V, Teufel A, Simiantonaki N, Biesterfeld S, Wehler T, Schuler M, Achenbach T, Junginger T, et al. Dissemination of hepatocellular carcinoma is mediated via chemokine receptor CXCR4. Br J Cancer 2006; 95:210-7.

11. Burger M, Hartmann T, Krome M, Rawluk J, Tamamura H, Fujii N, Kipps TJ, Burger JA. Small peptide inhibitors of the CXCR4 chemokine receptor (CD184) antagonize the activation, migration, and antiapoptotic responses of CXCL12 in chronic lymphocytic leukemia B cells. Blood 2005; 106:1824-30.

12. Zeng Z, Shi YX, Samudio IJ, Wang RY, Ling X, Frolova O, Levis M, Rubin JB, Negrin RR, Estey EH, Konoplev S, Andreeff M, Konopleva M. Targeting the leukemia microenvironment by CXCR4 inhibition overcomes resistance to kinase inhibitors and chemotherapy in AML. Blood 2009; 113:6215-24.

13. Ko SY, Park CJ, Park SH, Cho YU, Jang S, Seo EJ, Kim N, Kim DY, Koh KN, Im HJ, Seo JJ, Chi HS. High CXCR4 and low VLA-4 expression predicts poor survival in adults with acute lymphoblastic leukemia. Leuk Res 2014; 38:6570.

14. Sison EA, McIntyre E, Magoon D, Brown P. Dynamic chemotherapy-induced upregulation of CXCR4 expression: 
a mechanism of therapeutic resistance in pediatric AML. Mol Cancer Res 2013; 11:1004-16.

15. Brault L, Rovo A, Decker S, Dierks C, Tzankov A, Schwaller J. CXCR4-SERINE339 regulates cellular adhesion, retention and mobilization, and is a marker for poor prognosis in acute myeloid leukemia. Leukemia 2014; 28:566-76.

16. Vianello F, Villanova F, Tisato V, Lymperi S, Ho KK, Gomes AR, Marin D, Bonnet D, Apperley J, Lam EW, Dazzi F. Bone marrow mesenchymal stromal cells nonselectively protect chronic myeloid leukemia cells from imatinib-induced apoptosis via the CXCR4/CXCL12 axis. Haematologica 2010; 95:1081-9.

17. Heckmann D, Maier P, Laufs S, Wenz F, Zeller WJ, Fruehauf S, Allgayer H. CXCR4 Expression and Treatment with SDF-1alpha or Plerixafor Modulate Proliferation and Chemosensitivity of Colon Cancer Cells. Transl Oncol 2013; 6:124-32.

18. Domanska UM, Timmer-Bosscha H, Nagengast WB, Oude Munnink TH, Kruizinga RC, Ananias HJ, Kliphuis NM, Huls G, De Vries EG, de Jong IJ, Walenkamp AM. CXCR4 inhibition with AMD3100 sensitizes prostate cancer to docetaxel chemotherapy. Neoplasia 2012; 14:709-18.

19. Hui D, Proctor B, Donaldson J, Shenkier T, Hoskins P, Klasa R, Savage K, Chhanabhai M, Gascoyne RD, Connors JM, Sehn LH. Prognostic implications of extranodal involvement in patients with diffuse large B-cell lymphoma treated with rituximab and cyclophosphamide, doxorubicin, vincristine, and prednisone. Leuk Lymphoma 2010; 51:1658-67.

20. Moller MB, Pedersen NT, Christensen BE. Diffuse large B-cell lymphoma: clinical implications of extranodal versus nodal presentation--a population-based study of 1575 cases. Br J Haematol 2004; 124:151-9.

21. Friedberg JW. Relapsed/refractory diffuse large B-cell lymphoma. Hematology Am Soc Hematol Educ Program 2011; 2011:498-505.

22. Shaffer AL, 3rd, Young RM, Staudt LM. Pathogenesis of human B cell lymphomas. Annu Rev Immunol 2012; 30:565-610.

23. Perez-Andres M, Paiva B, Nieto WG, Caraux A, Schmitz A, Almeida J, Vogt RF, Jr., Marti GE, Rawstron AC, Van Zelm MC, Van Dongen JJ, Johnsen HE, Klein B, et al. Human peripheral blood B-cell compartments: a crossroad in B-cell traffic. Cytometry B Clin Cytom 2010; 78 Suppl 1:S47-60.

24. Bannard O, Horton RM, Allen CD, An J, Nagasawa T, Cyster JG. Germinal center centroblasts transition to a centrocyte phenotype according to a timed program and depend on the dark zone for effective selection. Immunity 2013; 39:912-24.

25. Muehlinghaus G, Cigliano L, Huehn S, Peddinghaus A, Leyendeckers H, Hauser AE, Hiepe F, Radbruch A, Arce $\mathrm{S}$, Manz RA. Regulation of CXCR3 and CXCR4 expression during terminal differentiation of memory B cells into plasma cells. Blood 2005; 105:3965-71.

26. Caron G, Le Gallou S, Lamy T, Tarte K, Fest T. CXCR4 expression functionally discriminates centroblasts versus centrocytes within human germinal center B cells. J Immunol 2009; 182:7595-602.

27. Kjeldsen MK, Perez-Andres M, Schmitz A, Johansen P, Boegsted M, Nyegaard M, Gaihede M, Bukh A, Johnsen HE, Orfao A, Dybkaer K. Multiparametric flow cytometry for identification and fluorescence activated cell sorting of five distinct B-cell subpopulations in normal tonsil tissue. Am J Clin Pathol 2011; 136:960-9.

28. Roy I, Evans DB, Dwinell MB. Chemokines and chemokine receptors: update on utility and challenges for the clinician. Surgery 2014; 155:961-73.

29. Beider K, Ribakovsky E, Abraham M, Wald H, Weiss L, Rosenberg E, Galun E, Avigdor A, Eizenberg O, Peled A, Nagler A. Targeting the CD20 and CXCR4 pathways in non-hodgkin lymphoma with rituximab and high-affinity CXCR4 antagonist BKT140. Clin Cancer Res 2013; 19:3495-507.

30. Azab AK, Runnels JM, Pitsillides C, Moreau AS, Azab F, Leleu X, Jia X, Wright R, Ospina B, Carlson AL, Alt C, Burwick N, Roccaro AM, et al. CXCR4 inhibitor AMD3100 disrupts the interaction of multiple myeloma cells with the bone marrow microenvironment and enhances their sensitivity to therapy. Blood 2009; 113:4341-51.

31. Calandra G, Bridger G, Fricker S. CXCR4 in clinical hematology. Curr Top Microbiol Immunol 2010; 341:17391.

32. Chang BY, Francesco M, De Rooij MF, Magadala P, Steggerda SM, Huang MM, Kuil A, Herman SE, Chang S, Pals ST, Wilson W, Wiestner A, Spaargaren M, et al. Egress of CD19(+)CD5(+) cells into peripheral blood following treatment with the Bruton tyrosine kinase inhibitor ibrutinib in mantle cell lymphoma patients. Blood 2013; 122:241224.

33. Menter T, Ernst M, Drachneris J, Dirnhofer S, Barghorn A, Went P, Tzankov A. Phenotype profiling of primary testicular diffuse large B-cell lymphomas. Hematol Oncol 2014; 32:72-81.

34. Moreno MJ, Bosch R, Dieguez-Gonzalez R, Novelli S, Mozos A, Gallardo A, Pavon MA, Cespedes MV, Granena A, Alcoceba M, Blanco O, Gonzalez-Diaz M, Sierra J, et al. CXCR4 expression enhances diffuse large B-cell lymphoma dissemination and decreases patient survival. J Pathol 2014;

35. Mazur G, Butrym A, Kryczek I, Dlubek D, Jaskula E, Lange A, Kuliczkowski K, Jelen M. Decreased expression of CXCR4 chemokine receptor in bone marrow after chemotherapy in patients with non-hodgkin lymphomas is a good prognostic factor. PLoS One 2014; 9:e98194.

36. de Rooij MF, Kuil A, Geest CR, Eldering E, Chang BY, Buggy JJ, Pals ST, Spaargaren M. The clinically active BTK inhibitor PCI-32765 targets B-cell receptor- and 
chemokine-controlled adhesion and migration in chronic lymphocytic leukemia. Blood 2012; 119:2590-4.

37. Beider K, Begin M, Abraham M, Wald H, Weiss ID, Wald O, Pikarsky E, Zeira E, Eizenberg O, Galun E, Hardan I, Engelhard D, Nagler A, et al. CXCR4 antagonist 4F-benzoyl-TN14003 inhibits leukemia and multiple myeloma tumor growth. Exp Hematol 2011; 39:282-92.

38. Hu S, Xu-Monette ZY, Tzankov A, Green T, Wu L, Balasubramanyam A, Liu WM, Visco C, Li Y, Miranda RN, Montes-Moreno S, Dybkaer K, Chiu A, et al. MYC/BCL2 protein coexpression contributes to the inferior survival of activated B-cell subtype of diffuse large B-cell lymphoma and demonstrates high-risk gene expression signatures: a report from The International DLBCL Rituximab-CHOP Consortium Program. Blood 2013; 121:4021-31; quiz 4250.

39. Tzankov A, Xu-Monette ZY, Gerhard M, Visco C, Dirnhofer S, Gisin N, Dybkaer K, Orazi A, Bhagat G, Richards KL, Hsi ED, Choi WW, van Krieken JH, et al. Rearrangements of MYC gene facilitate risk stratification in diffuse large B-cell lymphoma patients treated with rituximab-CHOP. Mod Pathol 2013;

40. Visco C, Tzankov A, Xu-Monette ZY, Miranda RN, Tai YC, Li Y, Liu WM, d'Amore ES, Li Y, Montes-Moreno S, Dybkaer K, Chiu A, Orazi A, et al. Patients with diffuse large B-cell lymphoma of germinal center origin with BCL2 translocations have poor outcome, irrespective of MYC status: a report from an International DLBCL rituximabCHOP Consortium Program Study. Haematologica 2013; 98:255-63.

41. Xu-Monette ZY, Wu L, Visco C, Tai YC, Tzankov A, Liu WM, Montes-Moreno S, Dybkaer K, Chiu A, Orazi A, Zu Y, Bhagat G, Richards KL, et al. Mutational profile and prognostic significance of TP53 in diffuse large B-cell lymphoma patients treated with R-CHOP: report from an International DLBCL Rituximab-CHOP Consortium Program Study. Blood 2012; 120:3986-96.

42. Rimsza LM, Leblanc ML, Unger JM, Miller TP, Grogan TM, Persky DO, Martel RR, Sabalos CM, Seligmann B, Braziel RM, Campo E, Rosenwald A, Connors JM, et al. Gene expression predicts overall survival in paraffinembedded tissues of diffuse large B-cell lymphoma treated with R-CHOP. Blood 2008; 112:3425-3433.

43. Schrader AJ, Lechner O, Templin M, Dittmar KE, Machtens S, Mengel M, Probst-Kepper M, Franzke A, Wollensak T, Gatzlaff P, Atzpodien J, Buer J, Lauber J. CXCR4/CXCL12 expression and signalling in kidney cancer. Br J Cancer 2002; 86:1250-6.

44. Mirisola V, Zuccarino A, Bachmeier BE, Sormani MP, Falter J, Nerlich A, Pfeffer U. CXCL12/SDF1 expression by breast cancers is an independent prognostic marker of disease-free and overall survival. Eur J Cancer 2009; 45:2579-87.

45. Drury LJ, Ziarek JJ, Gravel S, Veldkamp CT, Takekoshi T, Hwang ST, Heveker N, Volkman BF, Dwinell MB. Monomeric and dimeric CXCL12 inhibit metastasis through distinct CXCR4 interactions and signaling pathways. Proc Natl Acad Sci U S A 2011; 108:17655-60.

46. Moskovits N, Kalinkovich A, Bar J, Lapidot T, Oren M. p53 Attenuates cancer cell migration and invasion through repression of SDF-1/CXCL12 expression in stromal fibroblasts. Cancer Res 2006; 66:10671-6.

47. Kojima K, McQueen T, Chen Y, Jacamo R, Konopleva M, Shinojima N, Shpall E, Huang X, Andreeff M. p53 activation of mesenchymal stromal cells partially abrogates microenvironment-mediated resistance to FLT3 inhibition in AML through HIF-1alpha-mediated down-regulation of CXCL12. Blood 2011; 118:4431-9.

48. Visco C, Li Y, Xu-Monette ZY, Miranda RN, Green TM, Li Y, Tzankov A, Wen W, Liu WM, Kahl BS, d'Amore ES, Montes-Moreno S, Dybkaer K, et al. Comprehensive gene expression profiling and immunohistochemical studies support application of immunophenotypic algorithm for molecular subtype classification in diffuse large B-cell lymphoma: a report from the International DLBCL Rituximab-CHOP Consortium Program Study. Leukemia 2012; 26:2103-13.

49. Xu-Monette ZY, Moller MB, Tzankov A, MontesMoreno S, Hu W, Manyam GC, Kristensen L, Fan L, Visco C, Dybkaer K, Chiu A, Tam W, Zu Y, et al. MDM2 phenotypic and genotypic profiling, respective to TP53 genetic status, in diffuse large B-cell lymphoma patients treated with rituximab-CHOP immunochemotherapy: a report from the International DLBCL Rituximab-CHOP Consortium Program. Blood 2013; 122:2630-40.

50. Fu L, Lin-Lee YC, Pham LV, Tamayo A, Yoshimura L, Ford RJ. Constitutive NF-kappaB and NFAT activation leads to stimulation of the BLyS survival pathway in aggressive B-cell lymphomas. Blood 2006; 107:4540-8.

51. Young KH, Medeiros LJ, Chan WC. Diffuse large B-cell lymphoma. In: Orazi A, Weiss LM, Foucar K, Knowles DM, eds. Neoplastic Hematopathology. Philadelphia, PA, USA. Lippincott Willaims \& Wilkins; 2014:502-565. 